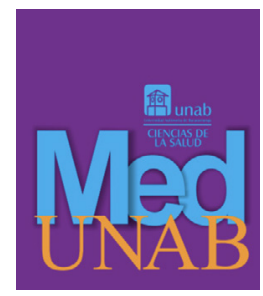

REVISTA DE LA FACULTAD

DE CIENCIAS DE LA SALUD

\title{
Estrés laboral, ansiedad y miedo al COVID-19 en médicos generales colombianos
}

Occupational Stress, Anxiety and Fear of COVID-19 in Colombian Physicians

Estresse ocupacional, ansiedade e medo da COVID-19 em clínicos gerais colombianos

Álvaro Monterrosa-Castro, Md., Esp. ${ }^{1}$ (D) Raúl Dávila-Ruiz, Est. ${ }^{2}$ (D) Alexa MejíaMantilla, Md. ${ }^{3}$ (D), Jorge Contreras-Saldarriaga, Md. ${ }^{4}$ (D), María Mercado-Lara, Md. ${ }^{3}$ (D), Chabeli Flores-Monterrosa, Est. ${ }^{5}$ (1)

1. Médico. Especialista en Ginecología y Obstetricia. Profesor Titular. Grupo de Investigación Salud de la Mujer. Facultad de Medicina. Universidad de Cartagena. Colombia.

2. Estudiante de Medicina. Grupo de Investigación Salud de la Mujer. Facultad de Medicina. Universidad de Cartagena. Colombia.

3. Médico. Grupo de Investigación Salud de la Mujer. Facultad de Medicina. Universidad de Cartagena. Colombia.

4. Médico. Estudiante de postgrado. Medicina Interna. Grupo de Investigación Salud de la Mujer. Facultad de Medicina. Universidad de Cartagena. Colombia.

5. Estudiante de Medicina. Universidad Libre Seccional Barranquilla. Grupo de Investigación Salud de la Mujer. Facultad de Medicina. Cartagena. Colombia.

Correspondencia. Álvaro Monterrosa Castro. La Matuna. Avenida Venezuela. Edificio City Bank. Oficina 6-A. Cartagena, Colombia. Email. alvaromonterrosa@gmail.com

\section{ARTICLE INFORMATION:}

Artículo recibido: 14 de abril 2020

Artículo aceptado: 03 de junio 2020

DOI: https://doi.org/10.29375/01237047.3890

Cómo citar. Monterrosa-Castro A, Dávila-Ruiz R, Mejía-Mantilla A, Contreras-Saldarriaga J, Mercado-Lara M, Flores-Monterrosa C. Estrés laboral, ansiedad y miedo al COVID-19 en médicos generales colombianos. MedUNAB. 2020;23(2): 195-213. doi: 10.29375/01237047.3890

\section{RESUMEN}

Introducción. Las epidemias pueden generar angustia en la población general y en los profesionales de la salud, y la pandemia causada por el virus del COVID-19 no es 
la excepción. El objetivo del presente estudio es determinar la presencia de síntomas de estrés laboral, ansiedad y miedo al COVID-19 en médicos generales, además de estimar la asociación según el ente territorial donde trabajaban. Metodología. Este es un estudio transversal que exploró síntomas y percepciones durante la pandemia del COVID-19 en médicos generales colombianos sometidos a cuarentena obligatoria que ejercieron su profesión en marzo del 2020. Previo consentimiento informado, anónima y voluntariamente, los participantes diligenciaron un formulario virtual con preguntas generales sobre COVID-19. El cuestionario buscaba encontrar problemas psicosomáticos sirviéndose de la Escala para el Trastorno de Ansiedad Generalizada (GAD-7, por sus siglas en inglés) y el FCV-19S (Fear of COVID-19). Los participantes se clasificaron en Municipio no capital o Municipio capital según el ente territorial en donde laboraban. Regresión logística entre el ente territorial (que acá es tomada como variable independiente) con los síntomas de ansiedad, estrés laboral y miedo al COVID-19 (que en este caso es tomado como variable dependiente). Resultados: Participaron 531 médicos generales con edad promedio de 30 años. El 73.3\% laboraban en Municipio capital. Un tercio de los encuestados presentó estrés laboral leve, mientras que el 6\% presentó estrés laboral alto o severo, esto sin diferencias entre los grupos $(\mathrm{p}<0.05)$. Se identificaron síntomas de ansiedad en el 72.9\%, más frecuente entre quienes laboraban en las capitales ( $p=0.044)$. El 37.1\% presentó síntomas de miedo al COVID-19 (FCV-19S). No se observó asociación en la regresión logística realizada. Discusión: Factores psicosociales y psicosomáticos asociados al miedo son el común denominador de los síntomas de ansiedad y estrés laboral en las pandemias. Conclusión: Siete de cada diez participantes presentó síntomas de ansiedad o estrés laboral, mientras que cuatro presentaron síntomas de FCV-19S. No se observó asociación con la clasificación del municipio donde laboraban.

Palabras clave:

Infecciones por Coronavirus; Médicos Generales; Estrés Laboral; Trastornos de Ansiedad; Miedo; Epidemias

\section{ABSTRACT}

Introduction. Epidemics can cause anxiety in the general population and health professionals. The pandemic caused by the COVID-19 virus is no exception. This study's objective is to identify symptoms of work-related stress, anxiety and fear of COVID-19 in physicians, as well as to discover their relation with the territorial body in which they work. Methodology: This is a cross-cutting study that explored the symptoms and perceptions of Colombian physicians forced to quarantine, who exercised their profession in March, 2020 during the COVID-19 pandemic. Having provided informed consent anonymously and voluntarily, participants completed a virtual form with general questions on COVID-19. The survey was aimed at finding psychosomatic problems using the Generalized Anxiety Disorder (GAD-7) scale and Fear of COVID-19 (FCV-19S) scale. Participants were classified as working in non-capital or capital municipalities according to the territorial body in which they practiced. Logistic regression between the territorial body (which was taken as an independent variable here) and symptoms of anxiety, work-related stress and fear of COVID-19 (which, in this case, were taken as dependent variables) was performed. Results: Five hundred and thirty-one general physicians participated, with an average age of 30. Seventythree point three percent practiced in a capital municipality. One third of the surveyed physicians presented mild work-related stress, while $6 \%$ presented high or severe work-related stress, without differences between groups $(\mathrm{p}<0.05)$. Symptoms of anxiety were found in $72.9 \%$ of the surveyed physicians, more frequently among those who practiced in capitals $(\mathrm{p}=0.044)$. Thirty-seven point one percent presented symptoms of fear of COVID-19 (FCV-19S). No relation was observed in the logistic regression. Discussion: Psychosocial and psychosomatic factors associated with fear are the common denominators of symptoms of anxiety and work-related stress during pandemics. Conclusion: Seven of every ten participants presented symptoms of anxiety or work-related stress, while four presented symptoms of FCV-19S. No relation was observed with the municipalities in which they worked.

Keywords:

Coronavirus Infection; General Practitioners; Occupational Stress; Anxiety Disorders; Fear; Epidemics 


\section{RESUMO}

Introdução. As epidemias podem causar angústia na população em geral e nos profissionais de saúde, e a pandemia causada pelo vírus COVID-19 não é exceção. O objetivo deste estudo é determinar a presença de sintomas de estresse ocupacional, ansiedade e medo da COVID-19 em clínicos gerais, além de estimar a associação de acordo com a entidade territorial em que trabalhavam. Metodología. Este é um estudo transversal que explorou sintomas e percepções durante a pandemia da COVID-19 em clínicos gerais colombianos submetidos à quarentena obrigatória que exerceram sua profissão em março de 2020. Após consentimento informado, anonimamente e voluntariamente, os participantes preencheram um formulário virtual com perguntas gerais sobre a COVID-19. O questionário procurou encontrar problemas psicossomáticos utilizando a Escala de Desordem de Ansiedade Generalizada (GAD-7, sigla em inglês) e o FCV-19S (Fear of COVID-19). Os participantes foram classificados em município não-capital ou município capital de acordo com a entidade territorial onde trabalhavam. Regressão logística entre a entidade territorial (que aqui é tomada como variável independente) com os sintomas de ansiedade, estresse ocupacional e medo da COVID-19 (que aqui é tomada como variável dependente). Resultados. Participaram 531 médicos de clínica geral com idade média de 30 anos. Do total, $73.3 \%$ trabalhavam no município da capital. Um terço dos entrevistados apresentou leve estresse ocupacional, enquanto $6 \%$ apresentou estresse ocupacional alto ou severo, isto sem diferenças entre os grupos $(\mathrm{p}<0,05)$. Os sintomas de ansiedade foram identificados em $72.9 \%$, mais frequentes entre os que trabalham nas capitais $(\mathrm{p}=0,044)$. Ademais, $37.1 \%$ tinham sintomas de medo da COVID-19 (FCV-19S). Nenhuma associação foi observada na regressão logística realizada. Discussão. Fatores psicossociais e psicossomáticos associados ao medo são o denominador comum dos sintomas de ansiedade e estresse ocupacional em pandemias. Conclusão. Sete em cada dez participantes apresentavam sintomas de ansiedade ou estresse no trabalho, enquanto quatro apresentavam sintomas do FCV-19S. Nenhuma associação foi observada com a classificação do município onde trabalhavam.

Palavras-chave:

Infecção por Coronavírus; Clínicos Gerais; Estresse Ocupacional; Transtornos de Ansiedade; Medo; Epidemias.

\section{Introducción}

En diciembre del 2019 se reportó por primera vez en Wuhan, China, un cuadro clínico compuesto por alteración respiratoria progresiva grave, fiebre, mialgias y fatiga, que posteriormente sería denominado COVID-19, causado por un nuevo coronavirus (SARS-CoV-2), y que se ha propagado rápidamente por todos los continentes $(1,2)$. Ha generado el brote de neumonía atípica más grande del mundo. A menudo es relacionado con el Síndrome Respiratorio Agudo Severo (SARS, por sus siglas en inglés) que surgió en el año 2003, y que tiene más rápida difusión, mayor tasa de infección y mayor mortalidad que el COVID-19 (3).

La Organización Mundial de la Salud (OMS) declaró en enero del 2020 al COVID-19 como una Emergencia de Salud Pública de Interés Internacional (Public Health Emergency of International Concern - PHEI), y en marzo del mismo año lo catalogó como pandemia (4). Las autoridades gubernamentales de todos los países, los organismos asesores en salud y las sociedades científicas, regionales o internacionales han tomado acciones y han brindado recomendaciones para afrontar los retos que trajo la infección en términos de sanidad, economía y seguridad social (5-7).

Las crisis de seguridad sanitaria frecuentemente generan estrés e incluso pánico en la población general, así como en los profesionales de salud, al sentir miedo a adquirir la enfermedad y morir a consecuencia de la infección $(3,8,9)$. Sim et al. evaluaron el impacto psicológico de la epidemia SARS en comunidades no infectadas y observaron presencia significativa de morbilidad psiquiátrica (10). A su vez, varios autores señalan que los trabajadores de la salud usualmente temen contagiar con la infección a sus familias, amigos o colegas y, asimismo, experimentan síntomas de estrés, ansiedad o depresión con implicaciones psicológicas a largo plazo (2,4,7,11-13). Kang et al. y Lai et al. han señalado que los profesionales de la salud han reportado importantes tasas de depresión, ansiedad, insomnio y estrés en la actual epidemia de COVID-19 $(8,11)$.

No existen suficientes estudios en Latinoamérica que valoren aspectos psicosociales en momentos de epidemias. 
Tampoco se identificaron estudios de síntomas de algunos eventos de la salud mental en médicos colombianos expuestos a la pandemia causada por el COVID-19, cuyo primer caso confirmado en Colombia fue informado por la prensa el 6 de marzo del 2020. Es necesario identificar la presencia de diversas alteraciones en salud mental (ansiedad o miedo) y de estrés laboral que tienen los profesionales de la salud colombianos en medio de la pandemia e identificar si la presencia es diferente, de acuerdo al trabajo en ciudades capitales o no, para establecer futuras recomendaciones a las instituciones gubernamentales o sanitarias, acciones preventivas o intervención de algún otro tipo. El objetivo de este estudio fue determinar la presencia de síntomas de estrés laboral, ansiedad y miedo al COVID-19, así como estimar si trabajar en municipio capital de departamento territorial se puede asociar a mayor presencia de las tres condiciones señaladas.

\section{Metodología}

Estudio transversal que hace parte del Proyecto DISEU (Dinámicas Psicosociales en Universitarios, brazo COVID-19), que pertenece a la línea de investigación Colectivos Universitarios. Se realizó una convocatoria escrita por las redes sociales WhatsApp, Facebook e Instagram y por correos electrónicos personales o de agremiaciones, para que médicos generales que ejercieran asistencialmente en marzo del 2020, participaran diligenciando entre el 1-5 de abril del mismo año, en la fase uno de confinamiento obligatorio decretado por el gobierno colombiano, un formulario electrónico especialmente diseñado. Se estableció en el protocolo que, si a los cinco días de trabajo de campo virtual no se alcanzaba el tamaño de muestra calculado, se reforzarían las invitaciones por las redes y la plataforma permanecería abierta por cinco días más. Para participar, los médicos generales debían laborar en marzo del 2020, ambulatoria u hospitalariamente en cualquiera de los niveles de complejidad de atención en instituciones públicas o privadas, cuyos pacientes presentasen cualquier tipo de afectación o condición de salud. El único criterio de exclusión establecido fue que el médico general participante no diligenciara completamente el formulario.

Se aplicó un formulario gratuito electrónico en Google Forms para realizar encuestas y adquirir estadísticas basadas en opinión. Se eligió la plataforma porque es de uso frecuente en ámbitos educativos, laborales y sociales, permite coordinar virtualmente y es de fácil diligenciamiento. Se solicitó a los participantes aplicar las respuestas en el período comprendido entre el 24 y el 30 de marzo del 2020, mientras Colombia cursaba cuarentena obligatoria relacionada con el COVID-19.

El formulario diseñado específicamente para este estudio contenía tres partes. La primera interrogaba sobre características sociodemográficas (género, edad y municipio en donde trabajaba el participante). La segunda estaba conformada por 25 preguntas generales sobre la percepción u opinión de aspectos relacionados con la epidemia del COVID-19 y la reacción médica a este, con respuesta binaria (Sí/No). Las preguntas inquirían sobre medidas gubernamentales, comportamiento ciudadano y expresiones de miedo a la pandemia. Estas que fueron discutidas por los investigadores y seleccionadas de una lluvia de ideas al respecto, tomadas de la información que generaban los noticieros colombianos y del exterior, así como de publicaciones en inglés sobre COVID-19 $(1,5,8,9,11)$. La tercera parte incluía la versión en español de tres escalas que han sido propuestas internacionalmente:

Cuestionario de problemas psicosomáticos, también denominado Test de estrés laboral. Es una herramienta sencilla de pocas preguntas, pero poco conocida, que permite analizar la presencia de síntomas psicosomáticos asociados al estrés y estimar la presencia y severidad de este en el puesto de trabajo. La versión en español fue adelantada por García-Izquierdo en 1993, y fue realizada tomando ítems de un extenso instrumento creado por Hock (14) en 1988 para explorar Síndrome de Burnout ("sentirse quedado o fundido"). Es aplicada en varios ambientes laborales, incluidos profesionales de la salud. No obstante, no se identificaron estudios en donde realizaran pruebas de confiabilidad. Consta de doce ítems tipo Likert, en los que se puntúan las respuestas de la siguiente manera: Nunca $=1$ punto, Casi nunca $=2$, Pocas veces $=3$, Algunas veces $=4$, Con relativa frecuencia $=5$ y Con mucha frecuencia $=6$. La sumatoria establece la presencia de estrés laboral: 0-12 puntos $=$ Sin síntomas de estrés; $13-24=$ Sin síntomas de estrés, pero en fase de alarma; 25-36 = Estrés leve; 37-48 = Estrés moderado, 49-60 = Estrés alto; y más de $61=$ Estrés grave. Puntuación igual o superior a 25 indica presencia de estrés laboral. Puntuaciones altas indican mayor respuesta psicosomática, que se corresponde a mayor nivel de estrés.

Escala del trastorno de ansiedad generalizada (GAD-7). Utilizada para evaluar problemas o síntomas de ansiedad en contextos clínicos y en población general. Tiene buena consistencia interna (Cronbach $=0.92$ ) y fiabilidad test-retest (correlación intraclase $=0.83$ ). Consta de siete preguntas tipo Likert: Nunca $=0$; Menos de la mitad de los días = 1; Más de la mitad de los días $=2$; y Casi todos los días $=3$. Ofrece 
puntuación total entre 0 y 21 puntos, que diagnostica al participante así: 0-4 puntos $=$ No se aprecian síntomas de ansiedad; 5-9 = Síntomas leves de ansiedad; 10-14 = Síntomas de ansiedad moderados; y 15-21 = Síntomas severos de ansiedad. Una puntuación de diez o más define la presencia de síntomas de ansiedad e indica la necesidad de valoración específica por un profesional especializado $(15,16)$.

Fear COVID-19 Scale [FCV-19S]. Recientemente desarrollada por Ahorsu et al., propuesta en marzo del 2020 y compuesta por siete ítems. Según los autores, cuenta con propiedades psicométricas robustas, confiable y válida para evaluar el miedo al COVID-19 en la población general; alfa de Cronbach: 0.82 y correlación intraclase: 0.72 (17). Solo existe la versión original en inglés, los ítems se tradujeron al español y luego se volvieron a traducir al inglés (back translation) siguiendo las directrices de Muñiz, Elosua y Hambleton (2013). No existe aún validación en español, por lo que se estimó la fiabilidad de la escala. Cada pregunta se responde tipo Likert con cinco opciones y se asignan puntos así: Totalmente en desacuerdo $=1 ;$ En desacuerdo $=2 ; \mathrm{Ni}$ de acuerdo ni en desacuerdo $=3$; De acuerdo $=4$ y Muy de acuerdo $=5$. Los autores de la versión original no señalaron el punto de corte. En el presente estudio, las tres primeras opciones se consideraron como respuestas negativas y las otras dos como positivas. Se definió como presencia de síntoma de miedo al COVID-19, obtener una puntuación que estuviese sobre el promedio de la población estudiada.

En la búsqueda realizada se observó que los datos disponibles sobre la cantidad de médicos generales en ejercicio en Colombia son contradictorios. Un informe de prensa señaló que para el 2011 se contaban 77,473 médicos generales (18). No obstante, otro indicó que en el 2018 se consideraban 65,939 profesionales (19). Información entregada por el Observatorio Laboral para la Educación Nacional certificó que entre el 2001 y el 2018 se habían graduado 73,092 médicos, de los cuales el $26 \%$ eran especialistas, por tanto, se estimaban en 54,092 los médicos generales egresados en ese lapso (20). Debido a lo anterior, se consideró subjetivamente la existencia actual de aproximadamente 80,000 médicos generales en Colombia. Con la calculadora online Netquest se estimaron 385 participantes a incluir en el estudio, considerándose el tamaño de muestra con heterogeneidad del $50 \%$, el nivel de confianza del $95 \%$ y el margen de error del $5 \%$.

Desde la plataforma de Google se descargó la base de datos que se genera automáticamente en Microsoft Excel y se realizó depuración de datos. Para observar los resultados de acuerdo con la jerarquía de los municipios donde laboraban los participantes, se crearon dos grupos: (1) Municipio no capital de departamento, y (2) Municipio capital de departamento. Se adelantó análisis con EPI-INFO-7.0 (Centers for Disease Control and Prevention, Atlanta, EE. UU.; 2008). Los datos continuos se expresaron en medianas $(\mathrm{Me})$ con rangos intercuartílicos (RI) y los categóricos en absolutos, porcentajes e intervalos de confianza al $95 \%$. Las diferencias entre grupos fueron evaluadas con la Prueba U de Mann-Whitney o ANOVA(según la homogeneidad de la varianza para variables continuas), y con MantelHaenszel o prueba de Fischer para las categóricas, según las frecuencias teóricas. Se realizó regresión logística no ajustada entre categoría del municipio (variable independiente) con síntomas de ansiedad, estrés laboral o miedo al COVID-19 (variable dependiente). El valor de $\mathrm{p}<0.05$ se consideró estadísticamente significativo.

Para conservar el completo anonimato, un investigador fue asignado para descargar la base de datos desde la plataforma y reemplazó la columna del correo electrónico del participante por un código individual alfanumérico. Al participar, los remitentes del formulario expresamente se identificaron como médicos generales; al diligenciarlo aceptaron los términos y concedieron el consentimiento informado que cumple con los lineamientos de acuerdo a la Declaración de Helsinki. Se tuvieron en cuenta las normas técnicas y científicas para la investigación en salud establecidas en Colombia en la Resolución 8430 de 1993. El estudio se clasificó como Investigación con riesgos mínimos (21). El grupo de investigación Salud de la Mujer y el proyecto de investigación DISEU cuentan con el aval institucional de la Universidad de Cartagena, Colombia. El investigador que descargó la base de datos, identificó a los participantes que presentaron síntomas de estrés laboral y ansiedad, reemplazó el código alfanumérico por el respectivo correo electrónico y envió individualmente cada notificación informando los resultados del estudio.

\section{Resultados}

En los primeros cinco días de abril del 2020 se recibieron por vía electrónica 548 formularios diligenciados y remitidos desde distintos correos electrónicos. Se encontraron 17 (el 3.1\%) incompletos y fueron descartados. Se realizó el estudio con la información aportada por 531 médicos generales, $37.9 \%$ por encima del tamaño de la muestra calculada.

Entre los participantes, 389 laboraban en municipio capital (el 73.3\%) y 142 en municipio no capital de los 
departamentos territoriales (el 26.7\%). La mediana de edad fue de 30 años. Más de la mitad estaban en el rango etario 21-30 y los que trabajaban en municipio capital tenían mayor edad que los primeros, $\mathrm{p}<0.05$. Más del $50 \%$ informaron ser médicas. La Tabla 1 presenta los datos sociodemográficos.

Las respuestas a los interrogantes sobre la percepción y opinión de aspectos relacionados con la pandemia y el desempeño de los encuestados se presentan en la Tabla 2. El 40\% manifestó haber sentido discriminación por su condición de profesional de la medicina, sin diferencias significativas entre los grupos. Los que laboraban en municipio capital informaron más frecuentemente haber creído tener síntomas relacionados con el COVID-19; sentir miedo de llevar la infección a casa; convivir con familiares que se encontraban en el grupo de alto riesgo para COVID-19 y cumplir el protocolo exhaustivo de desinfección al llegar a casa, comparados con los que laboraban en municipio no capital, $\mathrm{p}<0.05$.

Tabla 1. Características sociodemográficas.

\begin{tabular}{|c|c|c|c|c|c|}
\hline & & Todos: 531 & $\begin{array}{c}\text { Municipio no } \\
\text { capital } n=142 \\
(26.7 \%)\end{array}$ & $\begin{array}{c}\text { Municipio } \\
\text { capital } n=389 \\
(73.3 \%)\end{array}$ & $\mathbf{p}$ \\
\hline Edad (Me) - [RI] & & 30.0 [26-36] & $28.5[25-34]$ & $31.0[27-37]$ & $0.0002^{*}$ \\
\hline \multicolumn{6}{|l|}{ n (\%) [IC95\%] } \\
\hline & $21-30$ & $\begin{array}{c}277(52.2) \\
{[47.9-56.4]}\end{array}$ & $\begin{array}{c}87(61.3) \\
{[52.7-69.3]}\end{array}$ & $\begin{array}{c}190(48.8) \\
{[43.9-53.8]}\end{array}$ & $0.01 * *$ \\
\hline & $31-40$ & $\begin{array}{c}164(30.9) \\
{[27.1-34.9]}\end{array}$ & $\begin{array}{c}43(30.3) \\
{[22.9-38.5]}\end{array}$ & $\begin{array}{c}121(31.1) \\
{[26.7-35.9]}\end{array}$ & $0.85^{* *}$ \\
\hline \multirow[t]{3}{*}{ Rango de edad } & $41-50$ & $\begin{array}{c}49(9.2) \\
{[7.0-12.0]}\end{array}$ & $\begin{array}{c}6(4.2) \\
{[1.6-9.0]}\end{array}$ & $\begin{array}{c}43(11.0) \\
{[8.3-14.6]}\end{array}$ & $0.01 * *$ \\
\hline & $51-60$ & $\begin{array}{l}31(5.8) \\
{[4.1-8.2]}\end{array}$ & $\begin{array}{c}5(3.5) \\
{[1.1-8.0]}\end{array}$ & $\begin{array}{l}26(6.79) \\
{[4.6-9.6]}\end{array}$ & $0.16^{* *}$ \\
\hline & $61-70$ & $\begin{array}{c}10(1.9) \\
{[1.0-3.4]}\end{array}$ & $\begin{array}{c}1(0.7) \\
{[0.1-3.9]}\end{array}$ & $\begin{array}{c}9(2.3) \\
{[1.2-4.3]}\end{array}$ & $0.22 * *$ \\
\hline \multirow[t]{5}{*}{ Regiones } & Andina & $\begin{array}{l}220(41.4) \\
{[37.3-45.7]}\end{array}$ & $\begin{array}{c}85(59.9) \\
{[51.3-68.0]}\end{array}$ & $\begin{array}{c}135(34.7) \\
{[30.1-39.6]}\end{array}$ & $0.0001 * *$ \\
\hline & Caribe & $\begin{array}{c}294(55.4) \\
{[51.1-59.5]}\end{array}$ & $\begin{array}{c}50(35.2) \\
{[27.4-43.7]}\end{array}$ & $\begin{array}{c}244(62.7) \\
{[57.8-67.4]}\end{array}$ & $0.0001 * *$ \\
\hline & Pacífico & $\begin{array}{c}9(1.7) \\
{[0.9-3.2]}\end{array}$ & $\begin{array}{c}5(3.5) \\
{[1.1-8.0]}\end{array}$ & $\begin{array}{c}4(1.0) \\
{[0.4-2.6]}\end{array}$ & $0.04 * *$ \\
\hline & Orinoquía & $\begin{array}{c}7(1.3) \\
{[0.6-2.7]}\end{array}$ & $\begin{array}{c}1(0.7) \\
{[0.1-3.9]}\end{array}$ & $\begin{array}{c}6(1.5) \\
{[0.7-3.3]}\end{array}$ & $1.00^{* * *}$ \\
\hline & Amazonía & $\begin{array}{c}1(0.2) \\
{[0.1-1.1]}\end{array}$ & $\begin{array}{c}1(0.7) \\
{[0.1-3.9]}\end{array}$ & 0 & $0.26^{* * *}$ \\
\hline \multirow{2}{*}{ Género } & Masculino & $\begin{array}{c}215(40.5) \\
{[36.4-42.7]}\end{array}$ & $\begin{array}{c}58(40.8) \\
{[32.7-49.4]}\end{array}$ & $\begin{array}{c}157(40.4) \\
{[35.6-45.3]}\end{array}$ & \multirow{2}{*}{$0.91 * *$} \\
\hline & Femenino & $\begin{array}{c}316(59.5) \\
{[55.3-63.6]}\end{array}$ & $\begin{array}{c}84(59.1) \\
{[50.6-67.3]}\end{array}$ & $\begin{array}{c}232(59.6) \\
{[54.7-64.4]}\end{array}$ & \\
\hline
\end{tabular}

(*) Prueba U de Mann-Whitney. (**) Mantel-Haenszel. (***) Fisher.

Fuente: Elaboración propia. 
Tabla 2. Percepción y opinión de aspectos relacionados con la epidemia del COVID-19 y el desempeño de los encuestados.

Todos: 531

\section{Municipio no \\ capital $n=142$ \\ $(26.7 \%)$ \\ $(\mathbf{7 3 . 3 \% )}$}

$\mathbf{p}^{*}$

\section{n (\%) [IC95\%]}

\begin{tabular}{|c|c|c|c|c|c|}
\hline \multirow{2}{*}{$\begin{array}{l}\text { ¿Ha sentido que lo } \\
\text { discriminan por ser } \\
\text { personal sanitario? }\end{array}$} & No & $\begin{array}{c}324(61.0) \\
{[56.8-65.0]}\end{array}$ & $\begin{array}{c}96(67.6) \\
{[59.2-75.2]}\end{array}$ & $\begin{array}{l}228(58.6) \\
{[53.7-63.4]}\end{array}$ & \multirow{2}{*}{0.06} \\
\hline & Sí & $\begin{array}{c}207(39.0) \\
{[34.9-43.2]}\end{array}$ & $\begin{array}{c}46(32.4) \\
{[24.8-40.7]}\end{array}$ & $\begin{array}{c}161(41.4) \\
{[36.6-46.3]}\end{array}$ & \\
\hline \multirow{2}{*}{$\begin{array}{l}\text { ¿Ha creído tener } \\
\text { síntomas relacionados } \\
\text { con el COVID-19? }\end{array}$} & No & $\begin{array}{c}327(61.6) \\
{[57.4-65.5]}\end{array}$ & $\begin{array}{c}99(69.7) \\
{[61.4-77.1]}\end{array}$ & $\begin{array}{l}228(58.6) \\
{[53.7-46.3]}\end{array}$ & \\
\hline & Sí & $\begin{array}{l}204(38.4) \\
{[34.4 .42 .6]}\end{array}$ & $\begin{array}{c}43(30.3) \\
{[22.9-38.5]}\end{array}$ & $\begin{array}{c}161(41.4) \\
{[36.6-46.3]}\end{array}$ & $<0.05$ \\
\hline \multirow{2}{*}{$\begin{array}{l}\text { ¿Son confiables los } \\
\text { reportes de casos } \\
\text { que se muestran a la } \\
\text { comunidad? }\end{array}$} & No & $\begin{array}{l}499(94.0) \\
{[91.6-95.7]}\end{array}$ & $\begin{array}{l}131(92.5) \\
{[86.6-96.1]}\end{array}$ & $\begin{array}{l}368(94.6) \\
{[91.9-96.4]}\end{array}$ & \multirow{2}{*}{0.31} \\
\hline & Sí & $\begin{array}{c}32(6.0) \\
{[4.3-8.4]}\end{array}$ & $\begin{array}{c}11(7.7) \\
{[3.9-13.4]}\end{array}$ & $\begin{array}{c}21(5.4) \\
{[3.6-8.1]}\end{array}$ & \\
\hline \multirow{2}{*}{$\begin{array}{l}\text { ¿Opina que son } \\
\text { suficientes las pruebas de } \\
\text { detección que se hacen en } \\
\text { su comunidad? }\end{array}$} & No & $\begin{array}{c}503(94.8) \\
{[92.5-96.3]}\end{array}$ & $\begin{array}{c}134(94.4) \\
{[89.2-97.5]}\end{array}$ & $\begin{array}{c}369(94.9) \\
{[92.2-96.6]}\end{array}$ & \multirow{2}{*}{0.82} \\
\hline & Sí & $\begin{array}{c}28(5.3) \\
{[3.7-7.5]}\end{array}$ & $\begin{array}{c}8(5.6) \\
{[2.5-10.8]}\end{array}$ & $\begin{array}{l}20(5.1) \\
{[33.7 .8]}\end{array}$ & \\
\hline \multirow{2}{*}{$\begin{array}{l}\text { ¿Tiene miedo que se } \\
\text { presente mortalidad por } \\
\text { COVID-19, similar a } \\
\text { China o Europa? }\end{array}$} & No & $\begin{array}{c}43(8.1) \\
{[6.1-10.7]}\end{array}$ & $\begin{array}{c}14(9.9) \\
{[5.5-16.0]}\end{array}$ & $\begin{array}{c}29(7.5) \\
{[5.2-10.5]}\end{array}$ & \multirow{2}{*}{0.36} \\
\hline & Sí & $\begin{array}{l}488(91.9) \\
{[89.3-93.9]}\end{array}$ & $\begin{array}{c}128(90.1) \\
{[84.0-94.5]}\end{array}$ & $\begin{array}{c}360(92.5) \\
{[89.5-94.8]}\end{array}$ & \\
\hline \multirow{2}{*}{$\begin{array}{l}\text { ¿Considera suficientes } \\
\text { las medidas } \\
\text { gubernamentales frente } \\
\text { al COVID-19? }\end{array}$} & No & $\begin{array}{l}411(77.4) \\
{[73.6-80.7]}\end{array}$ & $\begin{array}{c}114(80.3) \\
{[72.8-86.5]}\end{array}$ & $\begin{array}{l}297(76.3) \\
{[71.9-80.3]}\end{array}$ & \multirow{2}{*}{0.33} \\
\hline & Sí & $\begin{array}{c}120(22.6) \\
{[19.2-26.3]}\end{array}$ & $\begin{array}{c}28(19.7) \\
{[13.5-27.2]}\end{array}$ & $\begin{array}{c}92(23.6) \\
{[19.7-28.1]}\end{array}$ & \\
\hline \multirow{2}{*}{$\begin{array}{l}\text { ¿Su comunidad ha } \\
\text { acatado adecuadamente } \\
\text { las medidas de } \\
\text { confinamiento } \\
\text { obligatorio? }\end{array}$} & No & $\begin{array}{l}515(97.0) \\
{[95.2-98.1]}\end{array}$ & $\begin{array}{c}138(97.2) \\
{[92.9-99.2]}\end{array}$ & $\begin{array}{c}377(96.9) \\
{[94.7-98.2]}\end{array}$ & \multirow{2}{*}{0.87} \\
\hline & Sí & $\begin{array}{c}16(3.0) \\
{[1.9-4.8]}\end{array}$ & $\begin{array}{c}4(2.8) \\
{[0.8-7.1]}\end{array}$ & $\begin{array}{c}12(3.1) \\
{[1.8-5.3]}\end{array}$ & \\
\hline \multirow{2}{*}{$\begin{array}{c}\text { ¿El equipo de } \\
\text { salud es suficiente } \\
\text { si se incrementan } \\
\text { marcadamente los casos? }\end{array}$} & No & $\begin{array}{l}481(90.6) \\
{[87.8-92.8]}\end{array}$ & $\begin{array}{c}130(91.5) \\
{[85.7-95.6]}\end{array}$ & $\begin{array}{c}351(90.2) \\
{[86.9-92.8]}\end{array}$ & \multirow{2}{*}{0.64} \\
\hline & Sí & $\begin{array}{c}50(9.4) \\
{[7.2-12.2]}\end{array}$ & $\begin{array}{c}12(8.4) \\
{[4.4-14.3]}\end{array}$ & $\begin{array}{c}38(9.8) \\
{[7.213 .1]}\end{array}$ & \\
\hline \multirow{2}{*}{$\begin{array}{c}\text { ¿Sentiría miedo de tener } \\
\text { necesidad de acudir como } \\
\text { paciente a unidad de } \\
\text { salud? }\end{array}$} & No & $\begin{array}{c}94(17.7) \\
{[14.6-21.1]}\end{array}$ & $\begin{array}{c}29(20.4) \\
{[14.1-28.0]}\end{array}$ & $\begin{array}{c}65(16.7) \\
{[13.3-20.7]}\end{array}$ & \multirow{2}{*}{0.32} \\
\hline & Sí & $\begin{array}{l}437(82.3) \\
{[78.8-85.3]}\end{array}$ & $\begin{array}{l}113(79.6) \\
{[72.0-85.9]}\end{array}$ & $\begin{array}{l}324(83.3) \\
{[79.3-86.7]}\end{array}$ & \\
\hline
\end{tabular}




\begin{tabular}{|c|c|c|c|c|c|}
\hline \multirow{2}{*}{$\begin{array}{l}\text { ¿Se siente satisfecho } \\
\text { con la labor que realiza } \\
\text { diariamente? }\end{array}$} & No & $\begin{array}{c}139(26.2) \\
{[22.6-30.0]}\end{array}$ & $\begin{array}{c}45(31.7) \\
{[24.1-40.0]}\end{array}$ & $\begin{array}{c}94(24.2) \\
{[20.2-28.7]}\end{array}$ & \multirow{2}{*}{0.08} \\
\hline & Sí & $\begin{array}{c}392(73.8) \\
{[69.9-77.3]}\end{array}$ & $\begin{array}{c}97(68.3) \\
{[60.0-75.9]}\end{array}$ & $\begin{array}{c}295(75.8) \\
{[71.3-78.8]}\end{array}$ & \\
\hline \multirow{2}{*}{$\begin{array}{c}\text { ¿Se siente protegido } \\
\text { por el sistema en } \\
\text { sus actividades } \\
\text { profesionales? }\end{array}$} & No & $\begin{array}{c}490(77.0) \\
{[73.2-90.4]}\end{array}$ & $\begin{array}{c}115(81.0) \\
{[73.5-87.1]}\end{array}$ & $\begin{array}{c}294(75.6) \\
{[71.1-79.6]}\end{array}$ & \multirow{2}{*}{0.19} \\
\hline & Sí & $\begin{array}{c}122(23.0) \\
{[19.6-26.7]}\end{array}$ & $\begin{array}{c}27(19.0) \\
{[12.9-26.4]}\end{array}$ & $\begin{array}{c}95(24.4) \\
{[20.4-28.9]}\end{array}$ & \\
\hline \multirow{2}{*}{$\begin{array}{l}\text { ¿Siente que está } \\
\text { contribuyendo a mejorar } \\
\text { la situación actual de la } \\
\text { pandemia? }\end{array}$} & No & $\begin{array}{c}63(11.9) \\
{[9.3-14.8]}\end{array}$ & $\begin{array}{c}23(16.2) \\
{[10.5-23.3]}\end{array}$ & $\begin{array}{c}40(10.3) \\
{[7.6-13.7]}\end{array}$ & \multirow{2}{*}{0.06} \\
\hline & Sí & $\begin{array}{c}468(88.1) \\
{[85.1-90.6]}\end{array}$ & $\begin{array}{c}119(83.8) \\
{[76.7-89.4]}\end{array}$ & $\begin{array}{c}349(89.7) \\
{[86.3-92.4]}\end{array}$ & \\
\hline \multirow{2}{*}{$\begin{array}{c}\text { ¿Siente angustia al } \\
\text { pensar que debe ir a } \\
\text { trabajar? }\end{array}$} & No & $\begin{array}{c}147(27.7) \\
{[24.0-31.6]}\end{array}$ & $\begin{array}{c}42(29.6) \\
{[22.2-37.8]}\end{array}$ & $\begin{array}{c}105(27.0) \\
{[22.8-31.6]}\end{array}$ & \\
\hline & Sí & $\begin{array}{c}384(72.3) \\
{[68.3-75.9]}\end{array}$ & $\begin{array}{c}100(70.4) \\
{[62.2-77.8]}\end{array}$ & $\begin{array}{c}284(73.0) \\
{[68.4-77.2]}\end{array}$ & 0.55 \\
\hline \multirow{2}{*}{$\begin{array}{l}\text { ¿Piensa que o se } \\
\text { puede contagiar con el } \\
\text { COVID-19 al realizar su } \\
\text { trabajo médico? }\end{array}$} & No & $\begin{array}{c}23(4.3) \\
{[2.9-6.4]}\end{array}$ & $\begin{array}{c}8(5.6) \\
{[2.5-10.8]}\end{array}$ & $\begin{array}{c}15(3.9) \\
{[2.3-6.3]}\end{array}$ & \multirow{2}{*}{0.37} \\
\hline & Sí & $\begin{array}{c}508(95.7) \\
{[93.5-97.1]}\end{array}$ & $\begin{array}{c}134(94.4) \\
{[89.2-97.5]}\end{array}$ & $\begin{array}{c}374(96.1) \\
{[93.7-97.6]}\end{array}$ & \\
\hline $\begin{array}{l}\text { ¿Ha considerado } \\
\text { renunciar a su trabajo }\end{array}$ & No & $\begin{array}{c}272(51.2) \\
{[46.9-55.4]}\end{array}$ & $\begin{array}{c}71(50.0) \\
{[41.5-58.5]}\end{array}$ & $\begin{array}{c}201(51.7) \\
{[46.7-56.6]}\end{array}$ & \multirow{2}{*}{0.73} \\
\hline $\begin{array}{c}\text { para protegerse y } \\
\text { proteger a su familia? }\end{array}$ & Sí & $\begin{array}{c}259(48.8) \\
{[44.5-53.0]}\end{array}$ & $\begin{array}{c}71(50.0) \\
{[41.5-58.5]}\end{array}$ & $\begin{array}{c}188(48.3) \\
{[43.4-53.3]}\end{array}$ & \\
\hline \multirow{2}{*}{$\begin{array}{c}\text { ¿Ha sentido decepción } \\
\text { en su trabajo médico } \\
\text { por las condiciones del } \\
\text { COVID-19? }\end{array}$} & No & $\begin{array}{c}226(42.6) \\
{[38.4-46.8]}\end{array}$ & $\begin{array}{c}56(39.4) \\
{[31.3-48.0]}\end{array}$ & $\begin{array}{c}170(43.7) \\
{[38.9-48.7]}\end{array}$ & \multirow{2}{*}{0.37} \\
\hline & Sí & $\begin{array}{c}305(57.4) \\
{[53.1-61.5]}\end{array}$ & $\begin{array}{c}86(60.6) \\
{[52.0-68.6]}\end{array}$ & $\begin{array}{c}219(56.3) \\
{[51.3-61.1]}\end{array}$ & \\
\hline \multirow{2}{*}{$\begin{array}{l}\text { ¿Ha sentido que lo } \\
\text { discriminan por ser } \\
\text { personal sanitario? }\end{array}$} & No & $\begin{array}{c}324(61.0) \\
{[56.8-65.0]}\end{array}$ & $\begin{array}{c}96(67.6) \\
{[59.2-75.2]}\end{array}$ & $\begin{array}{c}228(58.6) \\
{[53.7-63.4]}\end{array}$ & \multirow{2}{*}{0.06} \\
\hline & $\mathrm{Si}$ & $\begin{array}{c}207(39.0) \\
{[34.9-43.2]}\end{array}$ & $\begin{array}{c}46(32.4) \\
{[24.8-40.7]}\end{array}$ & $\begin{array}{c}161(41.4) \\
{[36.6-46.3]}\end{array}$ & \\
\hline \multirow{2}{*}{$\begin{array}{c}\text { ¿Tiene protocolo } \\
\text { exhaustivo de } \\
\text { desinfección al llegar a } \\
\text { casa? }\end{array}$} & No & $\begin{array}{c}49(9.3) \\
{[7.0-11.9]}\end{array}$ & $\begin{array}{c}25(17.6) \\
{[11.7-24.9]}\end{array}$ & $\begin{array}{c}24(6.2) \\
{[4.2-9.0]}\end{array}$ & \\
\hline & Sí & $\begin{array}{c}482(90.8) \\
{[88.0-92.9]}\end{array}$ & $\begin{array}{c}117(82.4) \\
{[75.1-88.3]}\end{array}$ & $\begin{array}{c}365(93.8) \\
{[91.0-95.8]}\end{array}$ & $<0.001$ \\
\hline \multirow{2}{*}{$\begin{array}{l}\text { ¿Siente miedo de llevar el } \\
\text { COVID-19 a su casa? }\end{array}$} & No & $\begin{array}{l}28(5.3) \\
{[3.6-7.5]}\end{array}$ & $\begin{array}{l}12(8.4) \\
{[4.4-14.3]}\end{array}$ & $\begin{array}{c}16(4.1) \\
{[2.5-6.6]}\end{array}$ & \multirow[b]{2}{*}{$<0.05$} \\
\hline & Sí & $\begin{array}{c}503(94.7) \\
{[92.4-96.3]}\end{array}$ & $\begin{array}{c}130(91.5) \\
{[85.7-95.6]}\end{array}$ & $\begin{array}{c}373(95.9) \\
{[92.4-97.4]}\end{array}$ & \\
\hline
\end{tabular}




\begin{tabular}{|c|c|c|c|c|c|}
\hline \multirow{2}{*}{$\begin{array}{l}\text { ¿Su familia tiene miedo } \\
\text { de que usted vuelva a } \\
\text { la casa infectado por el } \\
\text { COVID-19? }\end{array}$} & No & $\begin{array}{l}102(19.2) \\
{[16.0-22.7]}\end{array}$ & $\begin{array}{l}29(20.4) \\
{[14.1-28.0]}\end{array}$ & $\begin{array}{l}73(18.8) \\
{[15.2-22.9]}\end{array}$ & \multirow{2}{*}{0.66} \\
\hline & Sí & $\begin{array}{l}429(80.8) \\
{[77.2-83.9]}\end{array}$ & $\begin{array}{l}113(79.6) \\
{[72.0-85.9]}\end{array}$ & $\begin{array}{l}316(81.2) \\
{[77.1-84.8]}\end{array}$ & \\
\hline \multirow{2}{*}{$\begin{array}{c}\text { ¿Convive con familiares } \\
\text { que se encuentran en el } \\
\text { grupo de alto riesgo para } \\
\text { COVID-19? }\end{array}$} & No & $\begin{array}{l}225(42.4) \\
{[38.2-46.6]}\end{array}$ & $\begin{array}{c}71(50.0) \\
{[41.5-58.5]}\end{array}$ & $\begin{array}{c}154(39.6) \\
{[34.8-44.5]}\end{array}$ & \multirow{2}{*}{$<0.03$} \\
\hline & Sí & $\begin{array}{c}306(57.6) \\
{[53.3-61.7]}\end{array}$ & $\begin{array}{c}71(50.0) \\
{[41.5-58.5]}\end{array}$ & $\begin{array}{l}235(60.4) \\
{[55.5-65.1]}\end{array}$ & \\
\hline \multirow{2}{*}{$\begin{array}{l}\text { ¿Tiene miedo a ser } \\
\text { portador asintomático? }\end{array}$} & No & $\begin{array}{l}213(40.1) \\
{[36.0-44.3]}\end{array}$ & $\begin{array}{c}59(41.5) \\
{[33.3-50.1]}\end{array}$ & $\begin{array}{c}154(39.6) \\
{[34.8-44.5]}\end{array}$ & \multirow{2}{*}{0.68} \\
\hline & Sí & $\begin{array}{c}318(59.9) \\
{[55.6-63.9]}\end{array}$ & $\begin{array}{c}83(58.4) \\
{[49.9-66.6]}\end{array}$ & $\begin{array}{l}235(60.4) \\
{[55.5-65.1]}\end{array}$ & \\
\hline \multirow{2}{*}{$\begin{array}{c}\text { ¿Ha pensado en mudarse } \\
\text { de su casa mientras } \\
\text { dura la pandemia del } \\
\text { COVID-19? }\end{array}$} & No & $\begin{array}{c}171(32.3) \\
{[28.3-36.2]}\end{array}$ & $\begin{array}{c}44(31.0) \\
{[23.5-39.3]}\end{array}$ & $\begin{array}{l}127(32.6) \\
{[28.2-37.5]}\end{array}$ & \multirow{2}{*}{0.71} \\
\hline & Sí & $\begin{array}{c}360(67.8) \\
{[63.7-71.6]}\end{array}$ & $\begin{array}{c}98(69.0) \\
{[60.7-76.5]}\end{array}$ & $\begin{array}{l}262(67.3) \\
{[62.5-71.8]}\end{array}$ & \\
\hline \multirow{2}{*}{$\begin{array}{c}\text { ¿Ha tenido pesadillas con } \\
\text { el virus? }\end{array}$} & No & $\begin{array}{l}357(67.2) \\
{[63.1-71.0]}\end{array}$ & $\begin{array}{c}94(66.2) \\
{[57.8-73.9]}\end{array}$ & $\begin{array}{l}263(67.6) \\
{[62.8-72.1]}\end{array}$ & \multirow{2}{*}{0.75} \\
\hline & Sí & $\begin{array}{c}174(32.7) \\
{[28.9-36.8]}\end{array}$ & $\begin{array}{c}48(33.8) \\
{[26.1-42.2]}\end{array}$ & $\begin{array}{c}126(32.4) \\
{[27.9-37.2]}\end{array}$ & \\
\hline \multirow{2}{*}{$\begin{array}{l}\text { ¿Se siente estresado con } \\
\text { el COVID-19? }\end{array}$} & No & $\begin{array}{c}125(23.5) \\
{[20.1-27.3]}\end{array}$ & $\begin{array}{c}34(23.9) \\
{[17.2-31.8]}\end{array}$ & $\begin{array}{c}91(23.4) \\
{[19.5-27.8]}\end{array}$ & \multirow{2}{*}{0.89} \\
\hline & Sí & $\begin{array}{c}406(76.5) \\
{[72.6-79.8]}\end{array}$ & $\begin{array}{c}108(76.1) \\
{[68.2-82.8]}\end{array}$ & $\begin{array}{l}298(76.6) \\
{[72.1-80.5]}\end{array}$ & \\
\hline \multirow{2}{*}{$\begin{array}{l}\text { ¿Se siente angustiado con } \\
\text { el COVID-19? }\end{array}$} & No & $\begin{array}{c}409(77.0) \\
{[73.2-80.4]}\end{array}$ & $\begin{array}{c}113(79.6) \\
{[72.0-85.9]}\end{array}$ & $\begin{array}{l}296(76.1) \\
{[71.6-80.1]}\end{array}$ & \multirow{2}{*}{0.39} \\
\hline & Sí & $\begin{array}{c}122(23.0) \\
{[19.6-26.7]}\end{array}$ & $\begin{array}{c}29(20.4) \\
{[14.1-28.0]}\end{array}$ & $\begin{array}{c}93(23.9) \\
{[19.9-28.4]}\end{array}$ & \\
\hline
\end{tabular}

(*) Mantel-Haenszel

Fuente: Elaboración propia.

La Tabla 3 presenta los doce síntomas que valora el cuestionario de problemas psicosomáticos. Se encontró el Alfa de Cronbach en 0.873. Más de la mitad de los evaluados informaron presentar varios síntomas bastantes veces, casi siempre o siempre. A su vez, el $43 \%$ comunicó imposibilidad para conciliar el sueño, el $27 \%$ sentía tentación fuerte por no levantarse en la mañana a trabajar y el $20 \%$ presentaba cansancio extremo o agotamiento. No presentaban síntomas de estrés laboral: 20 (3.8\%) (IC 95\%: 2.4-5.7), tampoco tenían síntomas pero estaban en fase de alarma: 169 (31.8\%) (IC 95\%: 28.0-35.9), estrés laboral leve: 186 (35.0\%) (IC 95\%: 31.1-39.2), estrés laboral medio: $22(23.0 \%)$ (IC 95\%: 19.6-26.7), estrés laboral alto: 29 $(5.5 \%)$ (IC $95 \%: 3.8-7.7)$ y estrés laboral grave: $5(0.9 \%)$ (IC 95\%: 0.4-2.2). No se observaron diferencias en la clasificación del estrés laboral entre los dos grupos, $\mathrm{p}>0.05$. 
Tabla 3. Síntomas de estrés laboral. Cuestionario de problemas psicosomáticos. Población total y distribución según municipio de actividad laboral $n=531$

\begin{tabular}{|c|c|c|c|c|c|}
\hline \multirow[t]{2}{*}{ Ítems } & & $\begin{array}{c}\text { Nunca, casi } \\
\text { nunca, algunas } \\
\text { veces }\end{array}$ & Bastantes veces & Casi siempre & Siempre \\
\hline & \multicolumn{5}{|c|}{ n (\%) [IC95\%] } \\
\hline \multirow{3}{*}{$\begin{array}{l}\text { Imposibilidad } \\
\text { para conciliar el } \\
\text { sueño }\end{array}$} & Todos & $\begin{array}{c}302(56.9) \\
{[52.6-61.0]}\end{array}$ & $\begin{array}{c}138(26.0) \\
{[24.4-30.0]}\end{array}$ & $\begin{array}{c}61(11.5) \\
{[9.0-14.5]}\end{array}$ & $\begin{array}{c}30(5.6) \\
{[4.0-7.9]}\end{array}$ \\
\hline & $\begin{array}{l}\text { Municipio no } \\
\text { capital }\end{array}$ & $\begin{array}{c}72(52.1) \\
{[43.6-60.6]}\end{array}$ & $\begin{array}{c}34(23.9) \\
{[17.2-31.8]}\end{array}$ & $\begin{array}{c}26(18.3) \\
{[12.3-25.7]}\end{array}$ & $\begin{array}{c}8(5.6) \\
{[2.5-10.8]}\end{array}$ \\
\hline & $\begin{array}{l}\text { Municipio } \\
\text { capital }\end{array}$ & $\begin{array}{c}228(58.6) \\
{[53.7-63.4]}\end{array}$ & $\begin{array}{c}104(26.7) \\
{[22.6-31.3]}\end{array}$ & $\begin{array}{c}35(9.0) \\
{[6.5-12.3]}\end{array}$ & $\begin{array}{c}22(5.7) \\
{[3.8-8.4]}\end{array}$ \\
\hline \multirow{3}{*}{$\begin{array}{c}\text { Presencia de } \\
\text { jaquecas o } \\
\text { dolores de cabeza }\end{array}$} & Todos & $\begin{array}{c}312(58.8) \\
{[54.5-62.9]}\end{array}$ & $\begin{array}{c}123(23.2) \\
{[19.8-26.9]}\end{array}$ & $\begin{array}{c}63(11.9) \\
{[9.4-14.9]}\end{array}$ & $\begin{array}{c}33(6.2) \\
{[4.5-8.6]}\end{array}$ \\
\hline & $\begin{array}{l}\text { Municipio no } \\
\text { capital }\end{array}$ & $\begin{array}{c}90(63.4) \\
{[54.9-71.3]}\end{array}$ & $\begin{array}{c}30(21.1) \\
{[14.7-28.8]}\end{array}$ & $\begin{array}{c}16(11.3) \\
{[6.6-17.6]}\end{array}$ & $\begin{array}{c}6(4.2) \\
{[1.6-9.0]}\end{array}$ \\
\hline & $\begin{array}{l}\text { Municipio } \\
\text { capital }\end{array}$ & $\begin{array}{l}222(57.1) \\
{[52.1-61.9]}\end{array}$ & $\begin{array}{c}93(23.9) \\
{[19.9-28.4]}\end{array}$ & $\begin{array}{c}47(12.1) \\
{[9.2-15.7]}\end{array}$ & $\begin{array}{l}27(6.9) \\
{[4.8-9.9]}\end{array}$ \\
\hline \multirow{3}{*}{$\begin{array}{c}\text { Indigestión } \\
\text { o molestias } \\
\text { gastrointestinales }\end{array}$} & Todos & $\begin{array}{c}348(65.8) \\
{[61.6-69.7]}\end{array}$ & $\begin{array}{l}109(20.6) \\
{[17.4-24.3]}\end{array}$ & $\begin{array}{c}39(7.4) \\
{[5.4-9.9]}\end{array}$ & $\begin{array}{c}33(6.2) \\
{[4.5-8.6]}\end{array}$ \\
\hline & $\begin{array}{l}\text { Municipio no } \\
\text { capital }\end{array}$ & $\begin{array}{c}90(63.8) \\
{[55.3-71.7]}\end{array}$ & $\begin{array}{c}29(20.6) \\
{[14.2-28.2]}\end{array}$ & $\begin{array}{c}14(9.9) \\
{[5.5-16.1]}\end{array}$ & $\begin{array}{c}8(5.7) \\
{[2.5-10.9]}\end{array}$ \\
\hline & $\begin{array}{c}\text { Municipio } \\
\text { capital }\end{array}$ & $\begin{array}{c}258(66.5) \\
{[61.7-71.0]}\end{array}$ & $\begin{array}{c}80(20.6) \\
{[16.9-24.9]}\end{array}$ & $\begin{array}{c}25(6.4) \\
{[4.4-9.3]}\end{array}$ & $\begin{array}{l}25(6.4) \\
{[4.4-9.3}\end{array}$ \\
\hline \multirow{3}{*}{$\begin{array}{c}\text { Sensación } \\
\text { de cansancio } \\
\text { extremo o } \\
\text { agotamient }\end{array}$} & Todos & $\begin{array}{l}270(50.8) \\
{[46.6-55.1]}\end{array}$ & $\begin{array}{l}143(26.9) \\
{[23.3-30.9]}\end{array}$ & $\begin{array}{c}68(12.8) \\
{[10.2-15.9]}\end{array}$ & $\begin{array}{c}50(9.4) \\
{[7.2-12.2]}\end{array}$ \\
\hline & $\begin{array}{l}\text { Municipio no } \\
\text { capital }\end{array}$ & $\begin{array}{c}71(50.0) \\
{[41.5-58.5]}\end{array}$ & $\begin{array}{c}34(23.9) \\
{[17.2-31.8]}\end{array}$ & $\begin{array}{c}26(18.3) \\
{[12.3-25.7]}\end{array}$ & $\begin{array}{c}11(7.7) \\
{[3.9-13.4]}\end{array}$ \\
\hline & $\begin{array}{l}\text { Municipio } \\
\text { capital }\end{array}$ & $\begin{array}{c}199(51.2) \\
{[46.2-56.1]}\end{array}$ & $\begin{array}{c}109(28.0) \\
{[23.8-32.7]}\end{array}$ & $\begin{array}{c}42(10.8) \\
{[8.1-14.3]}\end{array}$ & $\begin{array}{c}39(10.0) \\
{[7.4-13.4]}\end{array}$ \\
\hline \multirow{3}{*}{$\begin{array}{c}\text { Tendencia a } \\
\text { comer, beber o } \\
\text { fumar más de lo } \\
\text { habitual }\end{array}$} & Todos & $\begin{array}{c}269(50.7) \\
{[46.4-54.9]}\end{array}$ & $\begin{array}{c}123(23.2) \\
{[19.8-26.9]}\end{array}$ & $\begin{array}{c}83(15.6) \\
{[12.8-19.0]}\end{array}$ & $\begin{array}{c}56(10.5) \\
{[8.21-13.4]}\end{array}$ \\
\hline & $\begin{array}{l}\text { Municipio no } \\
\text { capital }\end{array}$ & $\begin{array}{c}77(54.2) \\
{[45.7-62.6]}\end{array}$ & $\begin{array}{c}24(16.9) \\
{[11.1-24.1]}\end{array}$ & $\begin{array}{c}28(19.7) \\
{[13.5-27.2]}\end{array}$ & $\begin{array}{c}13(9.1) \\
{[5.0-15.1]}\end{array}$ \\
\hline & $\begin{array}{l}\text { Municipio } \\
\text { capital }\end{array}$ & $\begin{array}{c}192(49.4) \\
{[44.4-54.3]}\end{array}$ & $\begin{array}{c}99(25.4) \\
{[21.4-30.0]}\end{array}$ & $\begin{array}{c}55(14.1) \\
{[11.0-17.9]}\end{array}$ & $\begin{array}{c}43(11.0) \\
{[8.3-14.6]}\end{array}$ \\
\hline \multirow{3}{*}{$\begin{array}{l}\text { Disminución del } \\
\text { interés sexual }\end{array}$} & Todos & $\begin{array}{c}339(63.8) \\
{[59.7-67.8]}\end{array}$ & $\begin{array}{c}87(16.4) \\
{[13.5-20.0]}\end{array}$ & $\begin{array}{l}62(11.7) \\
{[9.2-14.7]}\end{array}$ & $\begin{array}{c}43(8.1) \\
{[6.1-10.7]}\end{array}$ \\
\hline & $\begin{array}{l}\text { Municipio no } \\
\text { capital }\end{array}$ & $\begin{array}{c}99(69.7) \\
{[61.4-77.1]}\end{array}$ & $\begin{array}{c}19(13.4) \\
{[8.2-20.1]}\end{array}$ & $\begin{array}{c}18(12.7) \\
{[7.7-19.3]}\end{array}$ & $\begin{array}{c}6(4.2) \\
{[1.6-9.0]}\end{array}$ \\
\hline & $\begin{array}{l}\text { Municipio } \\
\text { capital }\end{array}$ & $\begin{array}{l}240(61.7) \\
{[56.8-66.4]}\end{array}$ & $\begin{array}{c}68(17.5) \\
{[14.0-21.6]}\end{array}$ & $\begin{array}{c}44(11.3) \\
{[8.5-14.8]}\end{array}$ & $\begin{array}{c}37(9.5) \\
{[7.0-12.8]}\end{array}$ \\
\hline
\end{tabular}




\begin{tabular}{|c|c|c|c|c|c|}
\hline \multirow{3}{*}{$\begin{array}{c}\text { Respiración } \\
\text { entrecortada } \\
\text { o sensación de } \\
\text { ahogo }\end{array}$} & Todos & $\begin{array}{c}454(85.5) \\
{[82.2-88.2]}\end{array}$ & $\begin{array}{c}52(9.8) \\
{[7.5-12.6]}\end{array}$ & $\begin{array}{c}13(2.4) \\
{[1.4-4.1]}\end{array}$ & $\begin{array}{c}12(2.3) \\
{[1.3-3.9]}\end{array}$ \\
\hline & $\begin{array}{l}\text { Municipio no } \\
\text { capital }\end{array}$ & $\begin{array}{c}124(87.3) \\
{[80.7-92.3]}\end{array}$ & $\begin{array}{c}12(8.4) \\
{[4.4-14.3]}\end{array}$ & $\begin{array}{c}4(2.8) \\
{[0.8-7.1]}\end{array}$ & $\begin{array}{c}2(1.4) \\
{[0.2-5.0]}\end{array}$ \\
\hline & $\begin{array}{l}\text { Municipio } \\
\text { capital }\end{array}$ & $\begin{array}{c}330(84.8) \\
{[80.9-88.1]}\end{array}$ & $\begin{array}{c}40(10.3) \\
{[7.6-13.7]}\end{array}$ & $\begin{array}{c}9(2.3) \\
{[1.2-4.3]}\end{array}$ & $\begin{array}{c}10(2.6) \\
{[1.4-4.7]}\end{array}$ \\
\hline \multirow{3}{*}{$\begin{array}{l}\text { Disminución del } \\
\text { apetito }\end{array}$} & Todos & $\begin{array}{c}453(85.3) \\
{[82.0-88.1]}\end{array}$ & $\begin{array}{c}50(9.4) \\
{[7.2-12.2]}\end{array}$ & $\begin{array}{c}12(2.3) \\
{[1.3-3.9]}\end{array}$ & $\begin{array}{c}16(3.0) \\
{[1.9-4.8]}\end{array}$ \\
\hline & $\begin{array}{l}\text { Municipio no } \\
\text { capital }\end{array}$ & $\begin{array}{c}129(90.8) \\
{[84.8-95.0]}\end{array}$ & $\begin{array}{c}11(7.7) \\
{[3.9-13.4]}\end{array}$ & $\begin{array}{c}1(0.7) \\
{[0.1-3.9]}\end{array}$ & $\begin{array}{c}1(0.7) \\
{[0.1-3.9]}\end{array}$ \\
\hline & $\begin{array}{l}\text { Municipio } \\
\text { capital }\end{array}$ & $\begin{array}{c}324(83.3) \\
{[79.3-86.7]}\end{array}$ & $\begin{array}{c}39(10.0) \\
{[7.4-13.4]}\end{array}$ & $\begin{array}{l}11(2.8) \\
{[1.6-5.0]}\end{array}$ & $\begin{array}{c}15(3.9) \\
{[2.3-6.3]}\end{array}$ \\
\hline \multirow{3}{*}{$\begin{array}{c}\text { Temblores } \\
\text { musculares o } \\
\text { nerviosos }\end{array}$} & Todos & $\begin{array}{c}467(87.9) \\
{[84.9-90.4]}\end{array}$ & $\begin{array}{c}46(8.7) \\
{[6.6-11.4]}\end{array}$ & $\begin{array}{c}10(1.9) \\
{[1.0-3.4]}\end{array}$ & $\begin{array}{l}8(1.5) \\
{[0.8-2.9]}\end{array}$ \\
\hline & $\begin{array}{l}\text { Municipio no } \\
\text { capital }\end{array}$ & $\begin{array}{c}128(90.1) \\
{[84.0-94.5]}\end{array}$ & $\begin{array}{c}10(7.0) \\
{[3.43-12.6]}\end{array}$ & $\begin{array}{c}4(2.8) \\
{[0.8-7.1]}\end{array}$ & 0 \\
\hline & $\begin{array}{l}\text { Municipio } \\
\text { capital }\end{array}$ & $\begin{array}{c}339(87.1) \\
{[83.4-90.1]}\end{array}$ & $\begin{array}{c}36(9.2) \\
{[6.8-12.5]}\end{array}$ & $\begin{array}{c}6(1.5) \\
{[0.7-3.3]}\end{array}$ & $\begin{array}{c}8(2.1) \\
{[1.0-4.0]}\end{array}$ \\
\hline \multirow{3}{*}{$\begin{array}{c}\text { Pinchazos o } \\
\text { sensaciones } \\
\text { dolorosas }\end{array}$} & Todos & $\begin{array}{c}422(79.5) \\
{[75.8-82.7]}\end{array}$ & $\begin{array}{c}59(11.1) \\
{[8.7-14.1]}\end{array}$ & $\begin{array}{c}30(5.6) \\
{[4.0-7.9]}\end{array}$ & $\begin{array}{c}20(3.8) \\
{[2.4-5.7]}\end{array}$ \\
\hline & $\begin{array}{l}\text { Municipio no } \\
\text { capital }\end{array}$ & $\begin{array}{c}111(78.2) \\
{[70.5-84.7]}\end{array}$ & $\begin{array}{c}15(10.6) \\
{[6.0-16.8]}\end{array}$ & $\begin{array}{c}9(6.3) \\
{[2.9-11.7]}\end{array}$ & $\begin{array}{c}7(4.9) \\
{[2.0-9.9]}\end{array}$ \\
\hline & $\begin{array}{l}\text { Municipio } \\
\text { capital }\end{array}$ & $\begin{array}{l}311879.9) \\
{[75.7-83.6]}\end{array}$ & $\begin{array}{c}44(11.3) \\
{[8.5-14.8]}\end{array}$ & $\begin{array}{c}21(5.4) \\
{[3.6-8.1]}\end{array}$ & $\begin{array}{c}13(3.3) \\
{[2.0-5.6]}\end{array}$ \\
\hline \multirow{3}{*}{$\begin{array}{c}\text { Tentaciones } \\
\text { fuertes de no } \\
\text { levantarse por la } \\
\text { mañana }\end{array}$} & Todos & $\begin{array}{c}332(62.5) \\
{[58.3-66.5]}\end{array}$ & $\begin{array}{l}103(19.4) \\
16.3-23.0]\end{array}$ & $\begin{array}{c}56(10.5) \\
{[8.2-13.4]}\end{array}$ & $\begin{array}{c}40(7.5) \\
{[5.6-10.1]}\end{array}$ \\
\hline & $\begin{array}{l}\text { Municipio no } \\
\text { capital }\end{array}$ & $\begin{array}{c}78(54.9) \\
{[46.4-63.3]}\end{array}$ & $\begin{array}{c}27(19.0) \\
{[12.9-26.4]}\end{array}$ & $\begin{array}{c}22(15.5) \\
{[10.022 .5]}\end{array}$ & $\begin{array}{c}15(10.6) \\
{[6.0-16.8]}\end{array}$ \\
\hline & $\begin{array}{l}\text { Municipio } \\
\text { capital }\end{array}$ & $\begin{array}{c}254(65.3) \\
{[60.4-69.9]}\end{array}$ & $\begin{array}{c}76(19.5) \\
{[15.9-23.8]}\end{array}$ & $\begin{array}{c}34(8.7) \\
{[6.3-12.0]}\end{array}$ & $\begin{array}{c}25(6.4) \\
{[4.4-9.3]}\end{array}$ \\
\hline \multirow{3}{*}{$\begin{array}{c}\text { Tendencia } \\
\text { a sudar o } \\
\text { palpitaciones }\end{array}$} & Todos & $\begin{array}{c}453(85.3) \\
{[82.0-88.1]}\end{array}$ & $\begin{array}{c}52(9.8) \\
{[7.5-12.6]}\end{array}$ & $\begin{array}{c}13(2.4) \\
{[1.4-4.1]}\end{array}$ & $\begin{array}{c}13(2.4) \\
{[1.4-4.1]}\end{array}$ \\
\hline & $\begin{array}{l}\text { Municipio no } \\
\text { capital }\end{array}$ & $\begin{array}{c}122(85.9) \\
{[79.1-91.2]}\end{array}$ & $\begin{array}{l}15(10.6) \\
{[6.0-16.8]}\end{array}$ & $\begin{array}{c}4(2.8) \\
{[0.8-7.1]}\end{array}$ & $\begin{array}{c}1(0.7) \\
{[0.1-3.9]}\end{array}$ \\
\hline & $\begin{array}{l}\text { Municipio } \\
\text { capital }\end{array}$ & $\begin{array}{l}331(85.1) \\
{[81.2-88.3]}\end{array}$ & $\begin{array}{c}37(9.5) \\
{[7.0-12.8]}\end{array}$ & $\begin{array}{c}9(2.3) \\
{[1.2-4.3]}\end{array}$ & $\begin{array}{c}12(3.1) \\
{[1.8-5.3]}\end{array}$ \\
\hline
\end{tabular}

Fuente: Elaboración propia. 
Ocho de cada diez participantes informaron presentar, en las dos semanas evaluadas, algunos de los problemas que exploran en la GAD-7. Se encontró el Alfa de Cronbach en 0.793 . El 26\% se sintieron nerviosos o muy alterados más de la mitad de los días o casi todos los días. Lo anterior fue más frecuente entre quienes laboraban en municipios capitales $(\mathrm{p}<0.05)$. El 15\%, laborase o no en municipio capital, manifestó haber sentido miedo casi todos los días como si algo terrible fuese a suceder. En similar proporción afirmaron que diariamente no habían podido dejar de preocuparse. Las respuestas a la GAD-7 se presentan en la Tabla 4.
No presentaban síntomas de ansiedad: 144 (27.1\%) (IC 95\%: 23.5-31.0), leve: 178 (33.5\%) (IC 95\%: 29.6-37.6), moderado: 138 (26.0\%), (IC 95\% 22.430.0), severos: 71 (13.4\%) (IC 95\%: 10.7-16.5). No se observaron diferencias entre los dos grupos en: ausencia de síntomas de ansiedad, presencia leve o moderada, $\mathrm{p}>0.05$. El 15.2\% (IC 95\%: 11.9-19.1) de los médicos que laboraban en capitales presentaron síntomas de ansiedad severa y el 8.4\% (IC 95\%: 4.4-14.3) de los que laboraban en municipios no capitales, $\mathrm{p}=0.0443$.

Tabla 4. Síntomas de estrés laboral. Cuestionario de problemas psicosomáticos. Población total y distribución según municipio de actividad laboral $n=531$

\begin{tabular}{|c|c|c|c|c|c|}
\hline \multirow{2}{*}{ Ítems } & & Nunca & $\begin{array}{c}\text { Menos de la } \\
\text { mitad de los días }\end{array}$ & $\begin{array}{l}\text { Más de la mitad } \\
\text { de los días }\end{array}$ & $\begin{array}{c}\text { Casi todos los } \\
\text { días }\end{array}$ \\
\hline & \multicolumn{5}{|c|}{ n (\%) [IC 95\%] } \\
\hline \multirow{3}{*}{$\begin{array}{l}\text { Sentirse nervioso, } \\
\text { ansioso o muy } \\
\text { alterado }\end{array}$} & Todos & $\begin{array}{c}174(32.8) \\
{[28.9-36.9]}\end{array}$ & $\begin{array}{c}217(40.9) \\
{[36.8-45.1]}\end{array}$ & $\begin{array}{c}97(18.3) \\
{[15.2-21.8]}\end{array}$ & $\begin{array}{c}43(8.1) \\
{[6.1-10.7]}\end{array}$ \\
\hline & $\begin{array}{l}\text { Municipio no } \\
\text { capital }\end{array}$ & $\begin{array}{c}48(33.8) \\
{[26.1-42.2]}\end{array}$ & $\begin{array}{c}62(43.7) \\
{[35.4-52.2]}\end{array}$ & $\begin{array}{c}24(16.9) \\
{[11.1-24.1]}\end{array}$ & $\begin{array}{c}8(5.6) \\
{[2.5-10.8]}\end{array}$ \\
\hline & $\begin{array}{c}\text { Municipio } \\
\text { capital }\end{array}$ & $\begin{array}{c}126(32.4) \\
{[27.93-37.2]}\end{array}$ & $\begin{array}{c}155(39.8) \\
{[35.1-44.8]}\end{array}$ & $\begin{array}{c}73(18.8) \\
{[15.20-22.9]}\end{array}$ & $\begin{array}{l}35(9.0) \\
{[6.5-12.3]}\end{array}$ \\
\hline \multirow{3}{*}{$\begin{array}{l}\text { No ha podido } \\
\text { dejar de } \\
\text { preocuparse }\end{array}$} & Todos & $\begin{array}{c}114(21.5) \\
{[18.2-25.2]}\end{array}$ & $\begin{array}{l}223(42.0) \\
{[37.9-46.2]}\end{array}$ & $\begin{array}{c}106(20.0) \\
{[16.8-23.6]}\end{array}$ & $\begin{array}{c}88(16.6) \\
{[13.6-20.0]}\end{array}$ \\
\hline & $\begin{array}{l}\text { Municipio no } \\
\text { capital }\end{array}$ & $\begin{array}{c}35(24.6) \\
{[17.8-32.6]}\end{array}$ & $\begin{array}{c}58(40.8) \\
{[32.7-49.4]}\end{array}$ & $\begin{array}{c}28(19.7) \\
{[13.5-27.2]}\end{array}$ & $\begin{array}{l}21(14.8) \\
{[9.4-21.7]}\end{array}$ \\
\hline & $\begin{array}{l}\text { Municipio } \\
\text { capital }\end{array}$ & $\begin{array}{c}79(20.3) \\
{[16.6-24.6]}\end{array}$ & $\begin{array}{c}165(42.4) \\
{[37.6-47.4]}\end{array}$ & $\begin{array}{c}78(20.0) \\
{[16.4-24.3]}\end{array}$ & $\begin{array}{c}67(17.2) \\
{[13.8-21.3]}\end{array}$ \\
\hline \multirow{3}{*}{$\begin{array}{l}\text { Se ha preocupado } \\
\text { excesivamente } \\
\text { por diferentes } \\
\text { cosas }\end{array}$} & Todos & $\begin{array}{c}108(20.3) \\
{[17.1-24.0]}\end{array}$ & $\begin{array}{l}210(39.5) \\
{[35.5-43.8]}\end{array}$ & $\begin{array}{c}135(25.4) \\
{[21.9-29.3]}\end{array}$ & $\begin{array}{l}78(14.7) \\
{[11.9-17.9]}\end{array}$ \\
\hline & $\begin{array}{l}\text { Municipio no } \\
\text { capital }\end{array}$ & $\begin{array}{c}30(21.1) \\
{[14.7-28.8]}\end{array}$ & $\begin{array}{c}55(38.7) \\
{[30.7-47.3]}\end{array}$ & $\begin{array}{c}43(30.3) \\
{[22.9-38.5]}\end{array}$ & $\begin{array}{c}14(9.9) \\
{[5.5} \\
{[6.0]}\end{array}$ \\
\hline & $\begin{array}{c}\text { Municipio } \\
\text { capital }\end{array}$ & $\begin{array}{c}78(20.0) \\
{[16.4-24.3]}\end{array}$ & $\begin{array}{l}155(39.8) \\
{[35.1-44.8]}\end{array}$ & $\begin{array}{c}92(23.6) \\
{[19.7-28.1]}\end{array}$ & $\begin{array}{c}64(16.4) \\
{[13.1-20.5]}\end{array}$ \\
\hline \multirow{3}{*}{$\begin{array}{l}\text { Dificultad para } \\
\text { relajarse }\end{array}$} & Todos & $\begin{array}{l}123(23.2) \\
{[19.8-26.9]}\end{array}$ & $\begin{array}{c}201(37.8) \\
{[33.8-42.0]}\end{array}$ & $\begin{array}{c}146(27.5) \\
{[23.9-31.4]}\end{array}$ & $\begin{array}{c}61(11.5) \\
{[9.0-14.5]}\end{array}$ \\
\hline & $\begin{array}{l}\text { Municipio no } \\
\text { capital }\end{array}$ & $\begin{array}{c}35(24.6) \\
{[17.8-32.6]}\end{array}$ & $\begin{array}{c}48(33.8) \\
{[26.1-42.2]}\end{array}$ & $\begin{array}{c}47(33.1) \\
{[25.4-41.5]}\end{array}$ & $\begin{array}{c}12(8.4) \\
{[4.4-14.3]}\end{array}$ \\
\hline & $\begin{array}{l}\text { Municipio } \\
\text { capital }\end{array}$ & $\begin{array}{c}88(22.6) \\
{[18.7-27.0]}\end{array}$ & $\begin{array}{c}153(39.3) \\
{[34.6-44.3]}\end{array}$ & $\begin{array}{c}99(25.4) \\
{[21.4-30.0]}\end{array}$ & $\begin{array}{c}49(12.6) \\
{[9.7-16.3]}\end{array}$ \\
\hline \multirow{3}{*}{$\begin{array}{l}\text { Se ha sentido tan } \\
\text { intranquilo que } \\
\text { no podía estarse } \\
\text { quieto }\end{array}$} & Todos & $\begin{array}{l}213(40.1) \\
{[36.0-44.3]}\end{array}$ & $\begin{array}{c}176(33.1) \\
{[29.3-37.3]}\end{array}$ & $\begin{array}{c}99(18.6) \\
{[15.6-22.2]}\end{array}$ & $\begin{array}{c}43(8.1) \\
{[6.1-10.7]}\end{array}$ \\
\hline & $\begin{array}{l}\text { Municipio no } \\
\text { capital }\end{array}$ & $\begin{array}{c}54(38.0) \\
{[30.0-46.5]}\end{array}$ & $\begin{array}{c}51(35.9) \\
{[28.0-44.4]}\end{array}$ & $\begin{array}{c}33(23.2) \\
{[16.6-31.1]}\end{array}$ & $\begin{array}{c}4(2.8) \\
{[0.8-7.1]}\end{array}$ \\
\hline & $\begin{array}{l}\text { Municipio } \\
\text { capital }\end{array}$ & $\begin{array}{l}159(40.9) \\
{[36.1-45.8]}\end{array}$ & $\begin{array}{c}125(32.1) \\
{[27.7-36.9]}\end{array}$ & $\begin{array}{c}66(17.0) \\
{[13.6-21.0]}\end{array}$ & $\begin{array}{c}39(10.0) \\
{[7.42-13.4]}\end{array}$ \\
\hline
\end{tabular}




\begin{tabular}{|c|c|c|c|c|c|}
\hline \multirow{3}{*}{$\begin{array}{c}\text { Ha estado } \\
\text { irritado o } \\
\text { enfadado con } \\
\text { facilidad }\end{array}$} & Todos & $\begin{array}{c}148(27.9) \\
{[24.3-31.8]}\end{array}$ & $\begin{array}{c}219(41.2) \\
{[37.1-45.5]}\end{array}$ & $\begin{array}{c}117(22.0) \\
{[18.7-25.7]}\end{array}$ & $\begin{array}{c}47(8.8) \\
{[6.7-11.6]}\end{array}$ \\
\hline & $\begin{array}{l}\text { Municipio no } \\
\text { capital }\end{array}$ & $\begin{array}{c}47(33.1) \\
{[25.4-41.5]}\end{array}$ & $\begin{array}{c}57(40.1) \\
{[32.0-48.7]}\end{array}$ & $\begin{array}{c}31(21.8) \\
{[15.3-29.5]}\end{array}$ & $\begin{array}{c}7(4.9) \\
{[2.0-9.9]}\end{array}$ \\
\hline & $\begin{array}{l}\text { Municipio } \\
\text { capital }\end{array}$ & $\begin{array}{c}101(26.0) \\
{[21.9-30.5]}\end{array}$ & $\begin{array}{c}162(41.6) \\
{[36.8-46.6]}\end{array}$ & $\begin{array}{c}86(22.1) \\
{[18.3-26.5]}\end{array}$ & $\begin{array}{c}40(10.3) \\
{[7.6-13.7]}\end{array}$ \\
\hline \multirow{3}{*}{$\begin{array}{l}\text { Ha sentido miedo } \\
\text { como si fuera } \\
\text { a suceder algo } \\
\text { terrible }\end{array}$} & Todos & $\begin{array}{l}154(29.0) \\
{[25.3-33.0]}\end{array}$ & $\begin{array}{l}162(30.5) \\
{[26.7-34.5]}\end{array}$ & $\begin{array}{c}139(26.2) \\
{[22.6-30.1]}\end{array}$ & $\begin{array}{c}76(14.3) \\
{[11.6-17.5]}\end{array}$ \\
\hline & $\begin{array}{l}\text { Municipio no } \\
\text { capital }\end{array}$ & $\begin{array}{c}41(28.9) \\
{[21.6-37.1]}\end{array}$ & $\begin{array}{c}43(30.3) \\
{[22.9-38.5]}\end{array}$ & $\begin{array}{c}37(26.1) \\
{[19.1-34.1]}\end{array}$ & $\begin{array}{l}21(14.8) \\
{[9.4-21.7]}\end{array}$ \\
\hline & $\begin{array}{l}\text { Municipio } \\
\text { capital }\end{array}$ & $\begin{array}{l}113(29.0) \\
{[24.8-33.7]}\end{array}$ & $\begin{array}{c}119(30.6) \\
{[26.2-35.3]}\end{array}$ & $\begin{array}{c}102(26.2) \\
{[22.1-30.8]}\end{array}$ & $\begin{array}{c}55(14.1) \\
{[11.0-17.9]}\end{array}$ \\
\hline
\end{tabular}

Fuente: Elaboración propia.

La Tabla 5 presenta los resultados obtenidos con FCV-19S. La mitad informó no poder dormir porque le preocupaba el COVID-19 y a seis de cada diez se les aceleraba el corazón o sentían palpitaciones. No se observó diferencia entre los grupos ( $>00.05)$. Se encontró el Alfa de Cronbach en 0.598. El 37.1\% (IC 95\%: 33.1-41.2) presentó síntomas de miedo al COVID-19. El 74.5\% informó cuatro o más síntomas de miedos de los explorados por la escala y el promedio de número de miedos fue $4.1 \pm 1.0$.
No se observó que trabajar en municipio capital, con respecto a trabajar en municipio no capital, fuese un factor asociado a mayor presencia de síntomas de ansiedad OR: 0.80 (IC 95\%: 0.54-1.18), $\mathrm{p}=0.27$; estrés laboral OR: 0.99 (IC 95\%: 0.67-1.46), $\mathrm{p}=0.97$ o miedo al COVID-19 OR: 1.44 (IC95:0.96-2.16) $\mathrm{p}=0.07$.

Tabla 5. Síntomas de miedo al COVID-19. Fear COVID Scale (FLV-19S).

\begin{tabular}{|c|c|c|c|c|c|}
\hline & & Todos: 531 & $\begin{array}{c}\text { Municipio no } \\
\text { capital } n=142 \\
(26.7 \%)\end{array}$ & $\begin{array}{c}\text { Municipio } \\
\text { capital } n=389 \\
(\mathbf{7 3 . 3 \%})\end{array}$ & p (*) \\
\hline & & \multicolumn{4}{|c|}{ N (\%) [IC95\%] } \\
\hline \multirow{2}{*}{$\begin{array}{l}\text { Mucho miedo al } \\
\text { COVID-19 }\end{array}$} & No & $\begin{array}{c}94(17.7) \\
{[14.7-21.2]}\end{array}$ & $\begin{array}{c}29(20.4) \\
{[14.1-28.0]}\end{array}$ & $\begin{array}{c}65(16,71) \\
{[13,3-20,7]}\end{array}$ & \multirow{2}{*}{0,3} \\
\hline & Sí & $\begin{array}{c}437(82.3) \\
{[78.8-85.3]}\end{array}$ & $\begin{array}{c}113(79.5) \\
{[72,0-85,8]}\end{array}$ & $\begin{array}{l}324(83,29) \\
{[79,2-86,6]}\end{array}$ & \\
\hline \multirow{2}{*}{$\begin{array}{l}\text { Incomodidad } \\
\text { al pensar en el } \\
\text { COVID-19 }\end{array}$} & No & $\begin{array}{l}114(21.5) \\
{[18.2-25.2]}\end{array}$ & $\begin{array}{c}35(24,6) \\
{[17,8-32,5]}\end{array}$ & $\begin{array}{c}79(20,31) \\
{[16,6-24,5]}\end{array}$ & \multirow{2}{*}{0,3} \\
\hline & Sí & $\begin{array}{c}417(78.5) \\
{[74.8-81.8]}\end{array}$ & $\begin{array}{c}107(75,3) \\
{[67,4-82,1]}\end{array}$ & $\begin{array}{l}310(79,6) \\
{[75,4-83,3]}\end{array}$ & \\
\hline \multirow{2}{*}{$\begin{array}{l}\text { Las manos se } \\
\text { colocan húmedas } \\
\text { o sudorosas } \\
\text { cuando piensa en } \\
\text { el COVID-19 }\end{array}$} & No & $\begin{array}{l}163(30.7) \\
{[26.9-34.7]}\end{array}$ & $\begin{array}{c}47(33,1) \\
{[25,4-41,4]}\end{array}$ & $\begin{array}{c}116(29,8) \\
{[25,4-34,5]}\end{array}$ & \multirow{2}{*}{0,5} \\
\hline & Sí & $\begin{array}{l}368(69.3) \\
{[65.2-73.1]}\end{array}$ & $\begin{array}{c}95(66,9) \\
{[58,5-74,5]}\end{array}$ & $\begin{array}{c}273(70,1) \\
{[65,4-74,5]}\end{array}$ & \\
\hline
\end{tabular}




\begin{tabular}{|c|c|c|c|c|c|}
\hline \multirow{2}{*}{$\begin{array}{l}\text { Tiene miedo de } \\
\text { perder la vida } \\
\text { por el COVID-19 }\end{array}$} & No & $\begin{array}{l}154(29.0) \\
{[25.3-33.0]}\end{array}$ & $\begin{array}{c}41(28,8) \\
{[21,5-37,0]}\end{array}$ & $\begin{array}{c}113(29,0) \\
{[24,7-33,7]}\end{array}$ & \multirow{2}{*}{1} \\
\hline & Sí & $\begin{array}{c}377(71.0) \\
{[67.0-74.7]}\end{array}$ & $\begin{array}{c}101(71,1) \\
{[62,9-78,4]}\end{array}$ & $\begin{array}{c}276(70,9) \\
{[66,2-75,2]}\end{array}$ & \\
\hline \multirow{2}{*}{$\begin{array}{c}\text { Cuando ve } \\
\text { noticias e } \\
\text { historias sobre } \\
\text { COVID-19 se } \\
\text { pone nervioso o } \\
\text { ansioso }\end{array}$} & No & $\begin{array}{c}174(32.8 \\
{[28.91-36.9]}\end{array}$ & $\begin{array}{c}48(33,8) \\
{[26,0-42,2]}\end{array}$ & $\begin{array}{c}126(32,3) \\
{[27,9-37,1]}\end{array}$ & \multirow[b]{2}{*}{0,8} \\
\hline & Sí & $\begin{array}{l}357(67.2) \\
{[63.1-71.1]}\end{array}$ & $\begin{array}{c}94(66,2) \\
{[57,7-73,9]}\end{array}$ & $\begin{array}{c}263(67,6) \\
{[62,8-72,0]}\end{array}$ & \\
\hline \multirow{2}{*}{$\begin{array}{c}\text { No puedo } \\
\text { dormir porque } \\
\text { le preocupa el } \\
\text { COVID-19 }\end{array}$} & No & $\begin{array}{l}245(46.1) \\
{[41.9-50.4]}\end{array}$ & $\begin{array}{c}63(44,3) \\
{[36,0-52,9]}\end{array}$ & $\begin{array}{c}182(6,7) \\
{[41,8-51,7]}\end{array}$ & \multirow{2}{*}{0,6} \\
\hline & Sí & $\begin{array}{l}286(53.9) \\
{[49.6-58.1]}\end{array}$ & $\begin{array}{c}79(55,6) \\
{[47,0-63,9]}\end{array}$ & $\begin{array}{c}207(53,2) \\
{[48,2-58,1]}\end{array}$ & \\
\hline \multirow{2}{*}{$\begin{array}{l}\text { El corazón se } \\
\text { acelera o palpita } \\
\text { cuando piensa en } \\
\text { el COVID-19 }\end{array}$} & No & $\begin{array}{c}188(35.4) \\
{[31.5-39.6]}\end{array}$ & $\begin{array}{c}53(37,3) \\
{[29,3-45,8]}\end{array}$ & $\begin{array}{c}135(34,7) \\
{[30,1-39,5]}\end{array}$ & \multirow{2}{*}{0,6} \\
\hline & Sí & $\begin{array}{c}343(64.6) \\
{[60.4-68.5]}\end{array}$ & $\begin{array}{c}89(62,6) \\
{[54,1-70,6]}\end{array}$ & $\begin{array}{c}254(65,3) \\
{[60,4-69,8]}\end{array}$ & \\
\hline
\end{tabular}

(*) Mantel-Haenszel

Fuente: Elaboración propia.

\section{Discusión}

En la historia de la humanidad hay documentados muchos brotes epidémicos de importantes proporciones que la han diezmado sustancialmente $(4,8,22,23)$. La epidemia causada por el virus de la influenza en 1918 y la denominada "gripa española" que inició en los Estados Unidos causó una elevada mortalidad a nivel mundial (22).

La OMS creó en 1851 el Reglamento Sanitario Internacional (IHR, por sus siglas en inglés) y su última versión es del 2005. Este es un instrumento de derecho internacional que tiene entre sus objetivos ayudar a los países a evitar la propagación de las enfermedades (24). El IHR define a los PHEIC (Public Health Emergencies of International Concern) como eventos extraordinarios que constituyen riesgo para la salud pública de los estados, a través de la propagación de enfermedades de aparición inesperada, grave o repentina, que ameritan acción inmediata con respuesta internacional coordinada. Desde el año 2007 la OMS ha declarado seis PHEIC: pandemia de influenza H1N1 (2009), retroceso en la erradicación de la poliomielitis (2014), epidemia de ébola en África occidental (2014), brote del virus Zika (2016), epidemia de ébola Kivu-
Congo (2018-2019) y en 2019-2020 la pandemia por COVID-19 $(9,25)$.

En el presente estudio, realizado durante la fase de cuarentena poblacional preventiva, sin presencia de desbordamiento de la capacidad de atención del sistema sanitario nacional, se observó elevada presencia de síntomas de ansiedad, estrés laboral y miedo entre los profesionales que participaron, lo cual está documentado en esta epidemia por COVID-19 y en otras $(3,5,9-11,13)$. Xiao señaló que el COVID-19 acarrea alta tasa de morbilidad y mortalidad por la infección viral, así como afectaciones psicológicas y mentales (2). Hawryluck et al, desglosan los efectos psicológicos de las cuarentenas en tiempo de epidemias (3).

Las pandemias suelen instalarse de forma súbita y son de rápida propagación, generando diferentes impactos adversos, sobre todo de tipo social $(5,9,11)$. En el estudio se encontró que el 39\% de los médicos manifestaron haberse sentido discriminados por ser profesionales de la salud, lo cual fue más frecuentemente informado por los que trabajaban en municipio capital de departamento territorial. Varios autores han señalado que dos fenómenos sociológicos surgen fuertemente en épocas de epidemias contra los profesionales de la salud: la 
discriminación y la estigmatización $(4,9,23)$. Lo primero se refiere al tratamiento que recibe un individuo o un grupo con parcialidad o prejuicio. Lo segundo es una condición, rasgo, comportamiento o atributo que hace que la persona portadora sea incluida en una categoría social que genera una respuesta negativa y culturalmente inaceptable para la sociedad. Existe círculo vicioso entre estigmatización y discriminación (26). El concepto fue acuñado en 1963 por el sociólogo canadiense Erving Goffman y se ha señalado que, en medio de las epidemias, aflora el instinto egoísta de la supervivencia, lo que lleva a rechazar al otro y considerarlo probable fuente de contagio $(23,27)$.

La información adecuada, rápida y clara de los funcionarios de salud pública sobre la epidemia y las medidas gubernamentales o sanitarias contribuyen a reducir la presencia de discriminación hacia el profesional de la salud $(5,17,28)$. En la reciente epidemia de SARS se corroboró que la concentración del miedo genera estigmatización y discriminación $(3,9)$. Los medios masivos de comunicación, poderosa influencia en las actitudes públicas, pueden contribuir con la prevención evitando el uso de titulares dramáticos que puedan incentivar el miedo e incluso los sentimientos de pánico $(5,26,29)$. Varios autores han señalado que los profesionales de la salud, víctimas de discriminación en momentos de epidemias, pueden alcanzar mayor alteración emocional hasta en un $60 \%$ (12).

Más del 70\% de los evaluados manifestaron miedo de padecer COVID-19, ser fuente de contagio para sus familias, ser portadores asintomáticos e incluso morir. En la misma proporción se identificaron los síntomas de ansiedad, estrés laboral y las manifestaciones psicosomáticas. En varios de los ítems de las escalas utilizadas se observa la magnitud de la presencia de las somatizaciones. Este término fue propuesto a comienzos del siglo XX por el neurólogo y psicoanalista alemán Wilhem Shekel para explicar cómo un trastorno psicológico puede producir síntomas somáticos (30). Adolphs R. ha explicado ampliamente la neurobiología de la cognición social (31).

La somatización es un mecanismo de defensa inconsciente, mediante el cual un malestar emocional se convierte en un síntoma físico, desviando la atención del conflicto psicológico que genera ansiedad (32). La somatización es un complejo proceso cognitivo, afectivo y conductual en el que el individuo en una situación vital estresante experimenta síntomas físicos y los atribuye a una enfermedad biológica (33). La somatización está involucrada con la cognición social, proceso neurobiológico que permite interpretar adecuadamente los signos sociales para responder de manera apropiada y en consecuencia $(30,32,33)$. La somatización explica la interrelación entre los síntomas de ansiedad y estrés, que se observaron en el estudio. Debe ser motivo de preocupación la magnitud de los síntomas de estrés laboral u ocupacional identificado, ya que el estrés es factor importante para la presencia del Síndrome de Burnout (14). Varias estructuras anatómicas están implicadas en estos procesos: la corteza prefrontal y la amígdala, el cíngulo y la corteza frontal, premotora y motora $(31,34)$. Se puede especular que la presencia elevada de somatización observada en los profesionales participantes sea mecanismo de escape a la presencia de ansiedad y miedo que son elementos presentes en todas las epidemias.

El estrés, la ansiedad y el miedo son emociones o expresiones sintomáticas que son normales en fases iniciales ante estímulos agresores que se pueden moderar con patrones individuales de afrontamiento o somatización, y también se pueden desbordar llevando a la histeria o al pánico. Todo ello hace presencia en condiciones de epidemia $(3,5,8,11,17)$. Se pueden explicar la presencia y confluencia de los síntomas de estrés, ansiedad y miedo por las modificaciones que se suceden en los neurotransmisores. Está establecido un vínculo entre la disminución de algunos neurotransmisores y las emociones (34-35). La reducción de la serotonina, dopamina, endorfinas, acetilcolina, adrenalina y ácido $\gamma$-aminobutírico (GABA) se asocian con la ansiedad, obsesión, depresión, dificultad para controlar la ira, tristeza y emociones negativas $(34,36)$.

En general, no se observaron diferencias significativas entre los dos grupos, excepto síntomas de ansiedad severa, que no apoya la hipótesis de una mayor presencia de alteraciones psicosociales en los médicos que laboran en municipios capitales. Es muy posible que la incertidumbre personal y familiar, la imprevisibilidad de la severidad de la afectación, la angustia laboral y la intranquilidad y el miedo afecte al paciente por igual $(3,5,11)$. El miedo es un sistema de alarma cerebral que se activa cuando se detecta una amenaza real o ficticia en tiempo presente o futuro, incluso se puede asociar a experiencias pasadas (29). El miedo constituye un mecanismo de supervivencia para los seres vivos, especialmente el humano $(8,11,17,23,29)$. La amígdala cerebral cuenta con núcleos que reciben información sensorial y que, por medio de la serotonina, dopamina y la noradrenalina, regulan el condicionamiento al miedo $(35,37)$. Son los mismos receptores y neurotransmisores los que participan en los tres eventos sintomáticos explorados en el estudio, la magnitud de la presencia de 
síntomas de miedo fue similar para ansiedad y estrés, siendo posible una asociación entre ellos $(29,37)$.

Un claro ejemplo del accionar del hombre en las epidemias lo señala Saramago (38) en un cuadro epidémico de instalación súbita y bajo cuarentena que representa los comportamientos derivados del pánico, la angustia, la ansiedad desbordada, el egoísmo propio del humano para sobrevivir y el miedo colectivo. Sin distingos de poblaciones o culturas, las pandemias psíquicas causadas por el miedo viajan más lejos y más rápido que las propias enfermedades, infectando el imaginario colectivo $(11,23,34)$.

Alto riesgo de infección, equipamiento de protección personal inadecuado, ausencia de condiciones de seguridad o condiciones laborales de contratación no favorables, la falta en insumos biosanitarios o terapéuticos, aislamiento, agotamiento, jornadas extensas y falta de contacto familiar son otros factores que contribuyen a mayor presencia de síntomas de estrés o ansiedad, sentimientos de pánico, depresión y angustia en médicos que laboran en medio de epidemias $(1,3,5,17)$. Si bien en el estudio acá presentado algunos de estos factores no fueron expresamente interrogados, todos hacen parte de los eventos inherentes a las epidemias y han sido abordados desde la esfera psicosocial (10). Cambios en el estilo de vida a consecuencia de la epidemia se han asociado a veces a mayor alteración emocional en profesionales de la salud (12), por tanto, estos deben realizar esfuerzos cognitivos y conductuales como respuestas de afrontamiento a situaciones estresantes (10).

Los resultados obtenidos ratifican que los médicos no son inmunes a los problemas de salud mental, la afectación emocional o psíquica que experimentan puede ejercer efecto perjudicial en la capacidad para la toma de decisiones y del bienestar general. El estrés incesante, severo o crónico generará tendencia depresiva, aislamiento social interpersonal, disturbios del sueño, sensación de frustración o impotencia, Síndrome de Burnout y dificultad para la adecuada adaptación personal a los eventos relacionados con el devenir de la epidemia $(2-3,5,14,17)$. Cruz-Valdez et al., en un estudio transversal en profesionales de la salud durante la epidemia por H1N1, informaron prevalencia del Síndrome de Burnout del 24\% (cansancio emocional, despersonalización y baja realización personal) (28). En el mismo estudio, los médicos residentes, debido a sobrecarga de trabajo, turnos extenuantes y restricciones de salidas, presentaron mayor cansancio emocional, irritabilidad, insomnio, sensación de sobreesfuerzo físico y sobre todo ansiedad.
Los síntomas de ansiedad, como se ha anotado, se explican por mecanismos neuroendocrinos, donde el circuito cortico-estriado-talámico-cortical tiene rol protagónico $(31,34-36)$. Encontramos alta presencia de síntomas de ansiedad moderada y severa similares a la reportada en otros estudios adelantados en epidemias $(8,11)$. Nickel et al., encontraron en un hospital de tercer nivel de Toronto, durante la epidemia de SARS, que dos de cada tres profesionales de la salud tenían preocupaciones relacionadas con el virus, mientras que el $29 \%$ presentaba afectación emocional con impacto adverso en su estilo de vida y en la armonía familiar (12).

Este estudio tiene como fortaleza ser de los primeros en abordar aspectos de la salud mental y ocupacional de médicos generales colombianos en momentos de epidemia. Fue realizado con un cuestionario virtual de fácil diligenciamiento y con GAD-7, herramienta breve muy conocida y validada en diferentes escenarios. Tuvo adecuada fiabilidad con los participantes. Tiene como limitaciones las propias de los estudios transversales: establece asociaciones estadísticas y no causalidades; la forma virtual y masiva de invitación, así como la aceptación no validada de ser médico general pueden generar diferentes sesgos, especialmente de recordación y de selección, al no poder controlar a los participantes y conocer exactamente si son o no médicos generales o que realmente hubiesen atendido pacientes en marzo del 2020. Para evitar el abandono en medio de la aplicación del formulario, se dispuso como estrategia que el tiempo consumido al participante fuese poco, condición compleja de establecer y que se puede convertir en otra limitación. Adicionalmente, puede generar sesgo de información o de antecedentes. No se interrogó por el uso de equipos de bioseguridad ni el antecedente de rasgo de ansiedad familiar o personal, pues ambos pueden ser importantes factores de confusión. Aunque se incluyó un número de participantes mayor al tamaño de la muestra, puede existir sobreestimación o subestimación en los resultados, con posible sesgo de medición, sobre todo con el FCV-19S. El desarrollo y validación inicial de dicha escala fue realizado en población iraní bajo la pandemia del COVID-19 que hablaba dos dialectos; se identificó una sola publicación en lengua inglesa (17). Aún no está validado en español, siendo esto una importante limitación. Entre los médicos generales colombianos participantes tuvo escasa fiabilidad. El cuestionario de problemas psicosomáticos tuvo buena fiabilidad, fue utilizado para explorar doce somatizaciones con la debilidad de no haber identificado validaciones por otros autores, aunque ha sido utilizada en diversos escenarios laborales. Se ameritan amplios estudios en médicos colombianos laborando en condiciones de 
epidemia o pandemia para precisar el comportamiento e influencia de múltiples aspectos psicosomáticos y psicosociales.

Se recomienda a los funcionarios sanitarios y gubernamentales tener presente que las epidemias son situaciones cambiantes y con distintas fases (5). La adopción del aislamiento preventivo obligatorio, la puesta en práctica del distanciamiento social y medidas de higiene, así como las exigencias del cumplimiento ciudadano que buscan reducir la propagación de la enfermedad deben ser prudentemente exigidas $(3,39)$. Las autoridades en salud ocupacional y las empresas de riesgo laboral a las cuales están afiliados los médicos que cumplen su trabajo profesional deben explorar permanentemente la salud mental de estos trabajadores, ya que en el grupo estudiado se encontraron cifras importantes de síntomas de ansiedad y estrés laboral. La valoración clínica rutinaria permitirá identificar los casos con niveles elevados de ansiedad y estrés para aplicar acciones terapéuticas, sin dejar de lado los programas ocupacionales que incluyan medidas preventivas del estrés y la ansiedad laboral.

\section{Conclusión}

Siete de cada diez médicos generales valorados presentaban síntomas de ansiedad o estrés laboral, mientras que cuatro presentaban síntomas de miedo al COVID-19. Fue más frecuente la ansiedad severa entre los trabajadores en municipio capital. No obstante, trabajar en estos entes territoriales, no se asoció con mayor presencia de ninguna de las tres condiciones estudiadas. El distanciamiento social y el confinamiento inadecuadamente exigido, así como el incumplimiento ciudadano y la carencia de medidas de higiene, pueden llegar a ser factores generadores de miedo, ansiedad y estrés con mayor deterioro en la salud mental de la comunidad en general y de los profesionales de la salud.

\section{Agradecimientos}

Al grupo de médicos generales de Colombia que gentilmente dedicaron tiempo para aceptar la invitación y diligenciar el formulario propuesto.

A Teresa Beltrán-Barrios, integrante del Grupo de Investigación Salud de la Mujer, quien realizó los ajustes gramaticales y de estilo al manuscrito.

A los siguientes integrantes del grupo de investigación Salud de la Mujer que vinculados al proyectos DISEU, que participaron incentivando la convocatoria: QuintanaGuardo Freddy, Redondo-Mendoza Velia, OrdosgoitiaParra Estefana, Buelvas-de-la-Rosa Camila, MonterrosaBlanco Angélica, Contreras-Saldarriaga Jorge, GonzálezSequeda Andrea, Ahumada-Romero Diana, Pérez-Romero Diana, Salas-Becerra Cindy, Romero-Martínez Geraldine, Romero-Martínez Shairine, Espitia-Espitia Boris, Escobar-Galarza Johaney, López-García Teresa, PinzónLlanos Joseph, Marrugo-Flórez Martha.

\section{Conflictos de interés}

No hay conflictos de intereses que declarar.

\section{Financiación}

Los autores no recibieron recursos económicos por su participación en la investigación. El grupo de investigación Salud de la Mujer recibió apoyo logístico, financiero y aval de la Universidad de Cartagena, Colombia, para realizar el presente estudio por medio del Plan de Fortalecimiento y Sostenibilidad de Grupos de Investigación categorizados por COLCIENCIAS, Acta 064-2019 y Resolución 01430-2019.

\section{Referencias}

1. Li Q, Guan X, Wu P, Wang X, Zhou L, Tong Y, et al. Early transmission dynamics in Wuhan, China, of novel Coronavirus-Infected pneumonia. N Engl J Med. 2020;382(13):1199-1207. Disponible en: http:// www.nejm.org/doi/10.1056/NEJMoa2001316

2. Xiao C. A Novel Approach of Consultation on 2019 Novel Coronavirus (COVID-19)-Related Psychological and Mental Problems: Structured Letter Therapy. Psychiatry Investig. 2020;17(2):175176. https://doi.org/10.30773/pi.2020.0047

3. Hawryluck L, Gold WL, Robinson S, Pogorski S, Galea S, Styra R. SARS control and psychological effects of quarantine, Toronto, Canada. Emerg Infect Dis. 2004;10(7):1206-1212.

4. PAHO/WHO. [Internet]. WHO characterizes COVID-19 as a pandemic [citado 17 de abril de 2020] Disponible en: https://www.paho.org/hq/index.php?option=com co ntent\&view $=$ article \&id=15756: who-characterizescovid-19-as-a-pandemic\&Itemid=1926\&lang=en

5. OPS/OMS. Organización Panamericana de la Salud [Internet]. Consideraciones psicosociales y de salud mental durante el brote de COVID-19. [citado 17 de abril de 2020]. Disponible en:

https://www.paho.org/es/documentos/consideraciones- 
psicosociales-salud-mental-durante-brote-covid-19

6. Centers for Disease Control and Prevention. CDC. [Internet]. Coronavirus disease 2019 (COVID-19). Stress and coping. [citado 17 de abril de 2020]. Disponible en: https://www.cdc.gov/coronavirus/2019-ncov/daily-lifecoping/managing-stress-anxiety.html

7. Accini-Mendoza JL, Beltrán $\mathrm{N}$, Nieto-Estrada $\mathrm{VH}$, Ramos-Bolaños E, Pizarro-Gómez C, Rebolledo CE, et al. Declaration of consensus in critical medicine for multidisciplinary care of the patient with a suspected or confirmed diagnosis of covid-19. Acta Colombiana de Cuidado Intensivo. Available online 17 April 2020. In-Press. https://doi.org/10.1016/j.acci.2020.04.003

8. Kang L, Ma S, Chen M, Yang J, Wang Y, Li R, et al. Impact on mental health and perceptions of psychological care among medical and nursing staff in Wuhan during the 2019 novel coronavirus disease outbreak: A cross-sectional study. Brain Behav Immun. 2020 Mar 30. pii: S0889-1591(20)30348-2. https://doi.org/10.1016/j.bbi.2020.03.028

9. RanaW,MukhtarS,MukhtarS.Mentalhealthofmedical workers in Pakistan during the pandemic COVID-19 outbreak. Asian J Psychiatr. 2020;51:102080. https:// doi.org/10.1016/j.ajp.2020.102080

10. Sim K, Huak Chan Y, Chong PN, Chua HC, Wen Soon S. Psychosocial and coping responses within the community health care setting towards a national outbreak of an infectious disease. J Psychosom Res. 2010;68(2):195-202. https://doi.org/10.1016/j. jpsychores.2009.04.004

11. Lai J, Ma S, Wang Y, Cai Z, Hu J, Wei N, et al. Factors associated with mental health outcomes among health care workers exposed to coronavirus disease 2019. JAMA Netw Open. 20202;3(3):e203976. https://doi. org/10.1001/jamanetworkopen.2020.3976

12. Nickell LA, Crighton EJ, Tracy CS, Al-Enazy H, Bolaji Y, Hanjrah S, et al. Psychosocial effects of SARS on hospital staff: survey of a large tertiary care institution. CMAJ. 2004;170(5):793-798.

13. Khalid I, Khalid TJ, Qabajah MR, Barnard AG, Qushmaq IA. Healthcare workers emotions, perceived stressors and coping strategies during a MERS-CoV outbreak. Clin Med Res. 2016;14(1):7-14. https://doi. org $/ 10.3121 / \mathrm{cmr} .2016 .1303$

14. Frutos-Marín M. Relación entre los modelos de gestión de recursos humanos y los niveles de estrés laboral y Burnout en los profesionales de enfermería de atención especializada. Tesis, p: 499. [citado 10 de mayo de 2020]. Disponible en: https://buleria.unileon. es/bitstream/handle/10612/3508/tesis 9ef3ca. PDF? sequence $=1$ \&isAllowed $=y$

15. Spitzer RL, Kroenke K, Williams JB, Löwe B. A brief measure for assessing generalized anxiety disorder: the GAD-7. Arch Intern Med. 2006;166(10):1092-
1097.

16. García-Campayo J, Zamorano E, Ruiz MA, Pardo A, Pérez-Páramo M, López-Gómez V, et al. Cultural adaptation into Spanish of the generalized anxiety disorder-7 (GAD-7) scale as a screening tool. Health Qual Life Outcomes. 2010;8:8. https://doi. org/10.1186/1477-7525-8-8

17. Ahorsu DK, Lin CY, Imani V, Saffari M, Griffiths MD, Pakpour AH. The Fear of COVID-19 Scale: development and initial validation. Int J Ment Health Addict. 2020 Mar 27:1-9. https://doi.org/10.1007/ s11469-020-00270-8

18. ElEspectador.com. En Colombia hay un médico por cada 846 habitantes. Prensa (Colombia) 27 Febrero-2012. [citado 17 de abril de 2020]. Disponible en: https:// www.elespectador.com/noticias/salud/colombia-hay-unmedico-cada-846-habitantes-articulo-329003

19. López L. El país necesita más personal en salud. Prensa (Colombia) 24 mayo-2018. [citado 17 de abril de 2020]. Disponible en: https://www.elcolombiano. com/colombia/salud/el-pais-necesita-mas-personalen-salud-NC8747438

20. Sánchez AM. Por cada 1.000 habitantes en Colombia, hay alrededor de 1,5 médicos generales. Prensa (Colombia) 25 de marzo de 2020. [citado 17 de abril de 2020]. Disponible en: https://www. larepublica.co/economia/por-cada-1000-habitantesen-colombia-hay-aproximadamente-15-medicosgenerales-2982596

21. República de Colombia. Ministerio de Salud. Resolución 8430 de 1993. [citado 17 de abril de 2020]. Disponible en: https://www.minsalud.gov.co/sites/rid/Lists/ BibliotecaDigital/RIDE/DE/DIJ/RESOLUCION-8430DE-1993.PDF

22. Morens DM, Taubenberger JK. Influenza Cataclysm, 1918. N Engl J Med. 2018;379(24):2285-2287. https:// doi.org/10.1056/NEJMp1814447

23. O'Leary A, Jalloh MF, Neria Y. Fear and culture: contextualising mental health impact of the 2014-2016 Ebola epidemic in West Africa. BMJ Glob Health. 2018 Jun 22;3(3):e000924. https://doi.org/10.1136/ bmjgh-2018-000924

24. World Health Organization. WHO. International Health Regulations. (2005) $3^{\mathrm{a}}$ Ed. [Internet]. Paris (France). WHO Press; 2016 [citado 17 de abril de 2020]. 74 p. Disponible en:

https://apps.who.int/iris/bitstream/hand le/10665/246107/9789241580496-engpdf;jsessionid $=46612 \mathrm{~A} 19 \mathrm{DCFB} 39 \mathrm{C} 0 \mathrm{CC} 38 \mathrm{~A} 2 \mathrm{~B} 583 \mathrm{~F} 094 \mathrm{~A} 6$ ? sequ ence $=1$

25. World Health Organization. WHO. Strengthening health security by implementing the International Health Regulations (2005) [citado 17 de abril de 2020]. Disponible en: 
https://www.who.int/news-room/q-a-detail/what-arethe-international-health-regulations-and-emergencycommittees

26. Person B, Sy F, Holton K, Govert B, Liang A; National Center for Infectious Diseases/SARS Community Outreach Team. Fear and stigma: the epidemic within the SARS outbreak. Emerg Infect Dis. 2004;10(2):358-363.

27. Goffman Erving, Stigma: Notes on the Management of Spoiled Identity. $1^{\text {a }}$ Ed. New York (United State of America). Simon \& Schuster, Inc. 1986. [citado 17 de abril de 2020]. 156 p. Disponible en: https://www. amazon.com/-/es/Erving-Goffman/dp/0671622447

28. Cruz-Valdés B, Austrias-Corrales F, HerreraKienhelger L, Salas-Hernández J, Vegaz-Valero C. $\mathrm{ZV}$. Prevalence of burnout syndrome and coping strategies during an epidemiology because of AH1N1 influenza. Suma Psicológica. 201;18(2):17-28.

29. Dunsmoor JE, Paz R. Fear generalization and anxiety: behavioral and neural mechanisms. Biol Psychiatry. 2015;78(5):336-343. https://doi.org/10.1016/j. biopsych.2015.04.010

30. Lipowski Z J. Somatization: the concept and its clinical application. Am J Psychiatry. 1988;145(11):13581368.

31. Adolphs R. The neurobiology of social cognition. Curr Opin Neurobiol. 2001 Apr;11(2):231-239.

32. Duddu V, Isaac MK, Chaturvedi SK. Somatization, somatosensory amplification, attribution styles and illness behaviour: a review. Int Rev Psychiatry. 2006;18(1):25-33.

33. Scuccato R. Somatization Recenti Prog Med. 2019;110(2):100-105. https://doi.org/10.1701/3112.31007

34. Bocchio M, McHugh SB, Bannerman DM, Sharp T, Capogna M. Serotonin, amygdala and fear: assembling the puzzle. Front Neural Circuits. 2016;10:24. https:// doi.org/10.3389/fncir.2016.00024

35. ChaayaN,BattleAR,JohnsonLR.Anupdateon contextual fear memory mechanisms: Transition between Amygdala and Hippocampus. Neurosci Biobehav Rev. 2018;92:4354. https://doi.org/10.1016/j.neubiorev.2018.05.013

36. Möhler H. The GABA system in anxiety and depression and its therapeutic potential. Neuropharmacology. 2012;62(1):42-53. https://doi.org/10.1016/j.neuropharm.2011.08.040

37. Dymond S, Dunsmoor JE, Vervliet B, Roche B, Hermans D. Fear generalization in humans: systematic review and implications for anxiety disorder research. Behav Ther. 2015;46(5):561-582. https://doi.org/10.1016/j. beth.2014.10.001

38. Saramago J. Ensayo sobre la ceguera. Alfaguara. Madrid. 1995. 288p.

39. Brooks SK, Webster RK, Smith LE, Woodland L, Wessely S, Greenberg N, et al. The psychological impact of quarantine and how to reduce it: rapid review of the evidence. Lancet. 2020;395(10227):912-920. https://doi.org/ 10.1016/S0140-6736(20)30460-8 